\title{
Los ergs del desierto marginal de Atacama, Chile
}

\author{
José F. Araya Vergara \\ Departamento de Geografía, Universidad de Chile \\ Cas. 3387, Santiago de Chile
}

Recibido $1^{\circ}$ abril 2002; versión corregida y aceptada, 26 septiembre 2002.

\begin{abstract}
RESUMEN
Se estudia la morfología de estos ergs, su interacción con las condiciones topográficas pre-existentes y los pulsos formativos correspondientes. Estas dunas no son rasgos costeros en el presente, sino sistemas internos de cuenca y montaña, compuestos por conos de expansión dunar interconectados por cinturones dunares de valle. Los primeros son sistemas aklé y los segundos, conjuntos transverso-transgresivos y de dunas lineales complejas. En su formación se observa cinco pulsos. Por sus propiedades morfoscópicas y mineralógicas, las arenas fueron abastecidas por antiguas playas marinas, deflaciones formativas de yardangs y el fondo del valle fluvial principal más cercano. Debido a la interacción entre la deriva de arena y las cuencas pre-existentes, los pulsos formativos están representados tanto en los acumuladores principales de cuenca como en las formas de derivación entre cuencas. De acuerdo con las edades isotópicas de las terrazas marinas cercanas, los pulsos formativos operaron durante largo tiempo, en el Pleistoceno y quizás el Holoceno, de modo que las dunas lineales de derivación son formas polifásicas, incluyendo un pulso presente. Entre los elementos de teoría de ergs de desiertos montañosos, ha sido observado el efecto de vientos variables en dunas lineales de bypass y en asociaciones aklé, relaciones entre yardangs y procesos dunares formativos y la estructura dual (valle y cuenca) de mares de arena. Esta importante asociación morfológica es un Formenschatz de Mortensen, en el sentido de tesoro morfogenético.
\end{abstract}

Palabras claves: dunas de desierto marginal, dunas de cuenca y montaña, erg, yardang, estructura aklé.

\section{The ergs of the Atacama's marginal desert, Chile}

\begin{abstract}
The morphology of these ergs, their interaction with topographical preexisting conditions and their formative pulses are studied. These landforms are not present coastal features, but internal basin and range system, whose structure is a set of basin dune expansion fans connected among them by valley dune belts. The expansion fans are formed principally by aklé systems and the belts, by transversetransgressive sets and complex linear dunes. Five formative pulses are observed in these sand seas, represented by linear, transverse-transgressive and aklé patterns. As evidenced by their morphoscopic and mineralogical properties, sands were supplied by ancient marine beaches, yardang formative deflations and the nearest principal river valley. Because the interaction between sand drifts and the pre-existent basins, the formative pulses are represented both in principal basin stores and bypass landforms among basins. Because the isotopic age of the corresponding marine terraces, the formative pulses are thought to have operated during a long time, in the Pleistocene and perhaps the Holocene, so that bypass linear dunes are polyfasic landforms, including a present pulse. Among the elements on theory of ergs of mountainous deserts, have been observed the effect of variable winds on linear dunes of bypass and aklé assemblages, the relations between yardang and formative processes in dunes and the dual structure (valley and basin) of the ergs. This important assemblage of landforms is a Formenschatz of Mortensen, in the sense of morphogenetic treasure.
\end{abstract}

Key words: marginal desert dunes, basin and range dunes, erg, yardang, aklé pattern. 


\section{INTRODUCCIÓN}

Clásicamente, MORTENSEN (1927) distingue tres tipos de desierto en Chile, considerando los agentes exógenos principales: extremo, con predominante aunque rara acción del agua; moderado, con acción predominante del viento, y marginal, con acción conjunta entre viento y agua. Él observó que en los dos primeros tipos las dunas son relativamente escasas, pero que en el borde del desierto marginal de Copiapó tienen una extensión considerable (Fig. 1). Su ubicación al Norte del río Copiapó es destacada por BRÜGGEN (1950), quien atribuye a su cuenca el suministro principal de las arenas dunares. También señala el abastecimiento directo a partir de dunas del fondo del valle inferior, expresado en dunas que trepan los cerros del flanco norte, siguiendo la dirección de los vientos SW; deduce además el suministro indirecto a través de la costa, desde donde la masa debe haber sido transportada hasta los portezuelos interiores, como en el caso del valle Los Corralillos. También atribuye aporte de material a depósitos aluviales ocasionales y locales, cuyas arenas han sido retomadas por el viento. Similarmente, SEGERSTROM (1962) indica que estos sistemas se extienden desde la costa, $60 \mathrm{~km}$ hacia el interior, hasta $\mathrm{C}^{\circ}$ Medanoso a $1600 \mathrm{~m}$ de altitud, asumiendo el origen costero de sus arenas.

Actualmente, el conocimiento de ergs de desierto comparables con los de Atacama ha progresado mediante estudios de interacciones entre las dunas y el relieve preexistente. Para casos sin interferencia de relieve preexistente, se ha practicado recientes simulaciones computacionales (WIGGS 2001). Se está intentando comprender la morfogénesis de sistemas dunares a partir de dos controles derivados de las experiencias clásicas de BAGNOLD (1984): láminas de arena (slabs) que operen como «atractrices» y pendiente en el sitio de deposición (WERNER 1995). Con su manipulación, se reprodujo barjanes, dunas transversales y dunas lineales, cambiando el número de láminas arenosas y la variabilidad del viento.

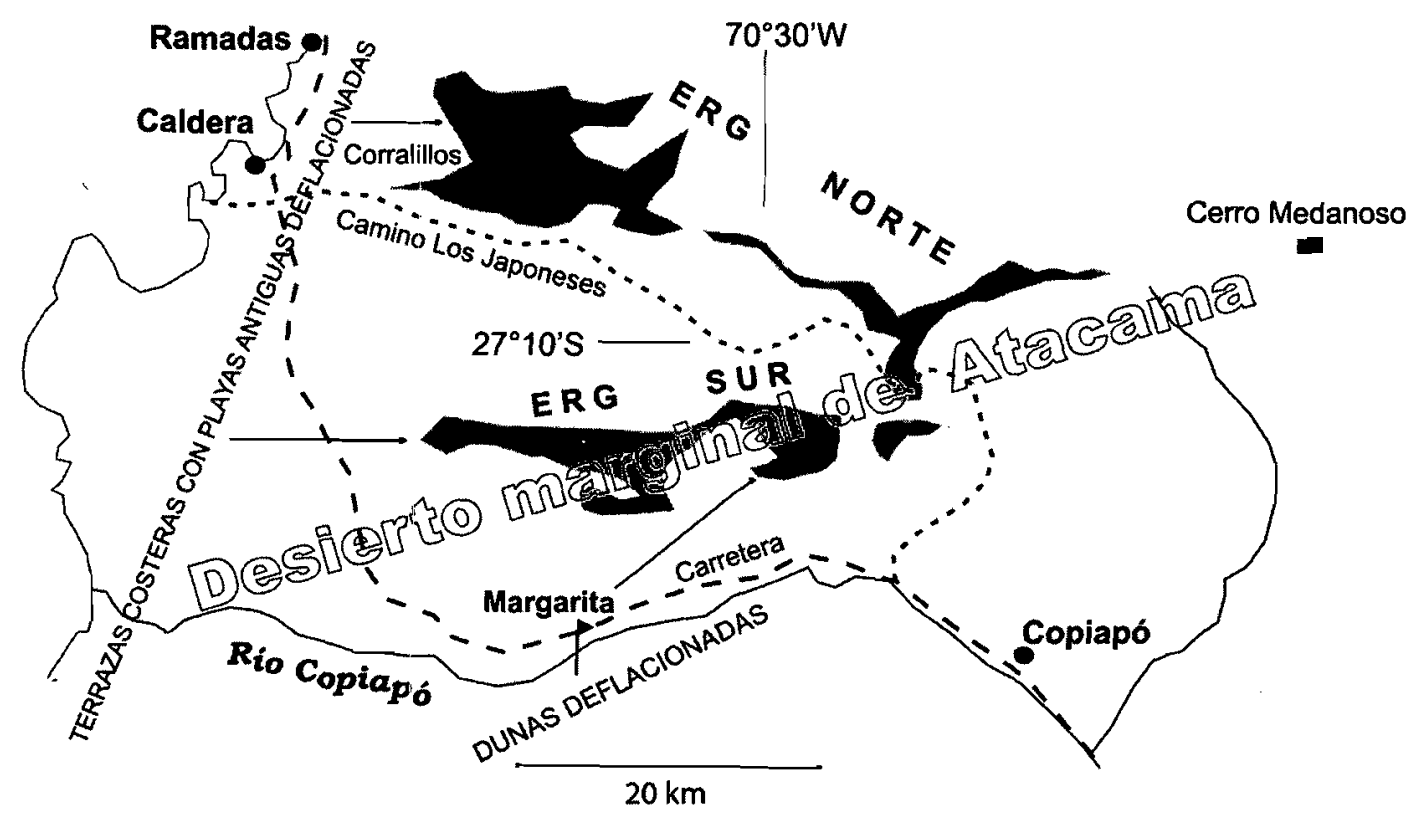

Fig. 1. Ubicación de los ergs en el extremo sur del Desierto de Atacama, Chile. Fig. 1. Location of the ergs in the southern end of the Atacama Desert, Chile. 
Consecuentemente, las asociaciones de formas permitieron a ANDERSON (1996) reconocer formas dunares que actuan como «atractrices» 0 «puntos de término» en el sistema de dinámica dunar, en función de la orientación de las crestas con respecto al viento medio y su variabilidad. Esta tendencia parece darse indiferentemente de las condiciones genéticas iniciales del experimento. Investigaciones de WILSON (1971) en cuencas saharianas concluyeron en modelos de desarrollo de ergs, según los que éste es radicalmente afectado por las formas preexistentes y su interacción con flujos secundarios.

La coacción entre el sistema de vientos y el relieve en la estructuración de grandes ergs queda indicada por los análisis de WASSON et al. (1988) en Australia, de GAY Jr. (1999) en el Sur de Perú, de ZAO SONGQIAO \& XIA XUNCHENG (1984) y MECKELEIN (1987) en Asia Central. Observaciones de BIGARELLA (2000) en la costa no desértica de Santa Catarina (Brasil) permiten precisar la noción de los llamados campos dunares reversos, debido a deflexión de vientos por barreras topográficas. Últimamente, la interpretación geomorfológica de estructuras sedimentarias ha sugerido modelos de dunas acrecionadas en condiciones de ascenso topográfico (MOUNTNEY \& HOWELL 2000). Para dunas parabólicas ascendentes imbricadas se ha medido el transporte eólico, siendo los valores de predicción más bajos que los observados (CRAIG 2000). Al respecto, se ha re-analizado la estructuración de cinturones barjánicos en el Sur del Perú (GAY Jr. 1999), pudiéndose comprender mejor la interacción entre dunas individuales y la formación de dunas compuestas. Se ha constatado además que la estructura dunar puede complicarse con elementos constituidos en diferentes tiempos (pulsos), hecho notorio en el Aklé (SE de Mauritania), donde hay contacto entre dunas fijas y móviles (GROVE 1958). Mediciones del tiempo de acreción en los Emiratos Árabes Unidos indican que para el Pleistoceno Tardío y el Holoceno los lapsos de acreción pueden ser relativamente cortos comparados con los de no acu- mulación (GOUDIE et al. 2000), lo que parece caracterizar a los sistemas desérticos (STOKES et al. 1997b).

La observación general de los ergs de Atacama (Fig. 2) revela su complejidad y que hay que analizarlos considerando la interrelación entre los sistemas componentes. Similar corolario se extrae al revisar la exposición de WIGGS (2001) sobre el conocimiento actual de las dunas de desierto y de los procedimientos para obtenerlo.

En consecuencia, el propósito de este trabajo es conocer la morfología de los ergs de Atacama, la coacción entre su estructuración y la forma de las cuencas preexistentes y las etapas de su formación. Se pretende además contribuir al enriquecimiento de la teoría acerca de las dunas de desierto.

\section{MATERIALES Y MÉTODOS}

\section{Emplazamiento de los ergs}

Estos sistemas se encuentran en cuencas intermontanas del que MORTENSEN (1927) llama desierto marginal en Atacama, interconectadas por valles o portezuelos que sustentan cinturones dunares (Fig. 1). En conjunto, conforman dos ergs, norte y sur, comunicados con la costa por fondos de valle a la altitud de la terraza costera alta ( 200$250 \mathrm{~m}$, Fig. 2), sin solución de continuidad topográfica. Este contacto puede darse quizás hasta elevaciones de $290 \mathrm{~m}$, altitud máxima de las terrazas costeras encontrada por MORTIMER (1973). Sobre estas terrazas hay antiguas playas, descritas como cordones arqueados de grava por SEGERSTROM (1962), quien dedujo que la superficie de las terrazas debe haber sido deflacionada, siendo fuente de las dunas instaladas en cuencas interiores. Estos cordones están principalmente a altitudes entre 50 y $100 \mathrm{~m}$. Algunos fueron mapeados por TRICART (1965), quien describe además depósitos de playa hasta $260 \mathrm{~m}$ de altitud. Se aprecia, pues, que los valles que sustentan los mares de arena están conectados con antiguas playas marinas. Las más altas se observan entre $250 \mathrm{~m}$ 


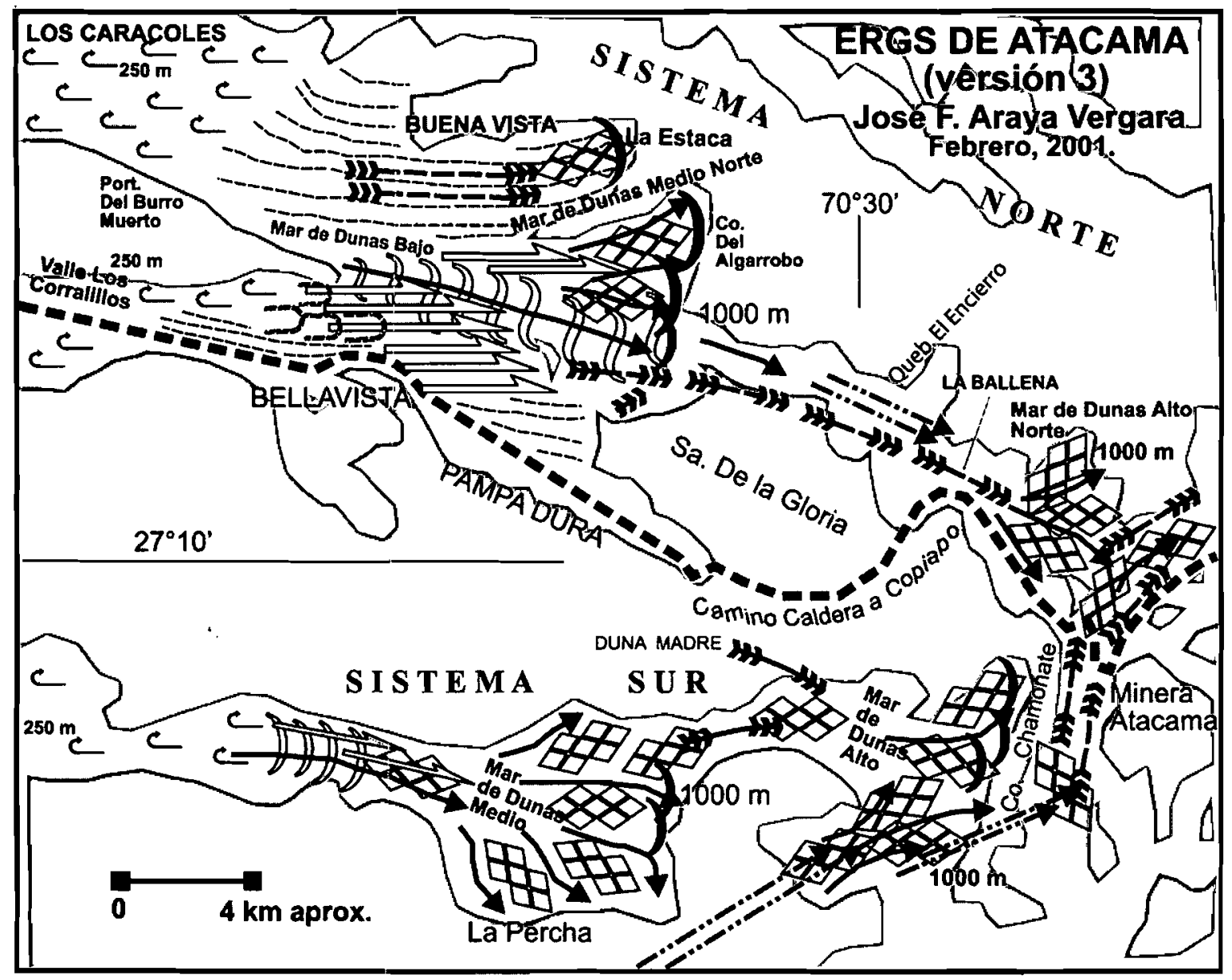

LEYENDA

TERRENOS NO DUNARES

De deflación desde playas marinas de la terraza principal antigua

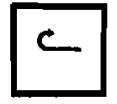
SISTEMAS DUNARES DE CUENCAS

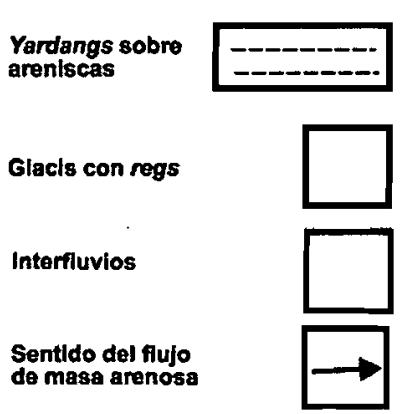

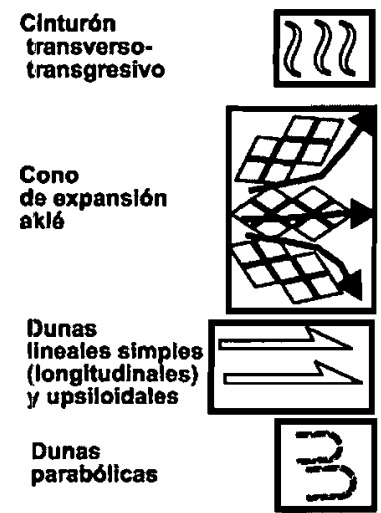

Dunas parabollicas,transgresivas, barjanoides, reversas y anidadas del pulso presente activo SISTEMAS REFERIDOS A BARRERAS TOPOGRAFICAS

A) Cinturón de derivación (bypass)

Transgresivo

Fig. 2. Mapa geomorfológico general de los ergs de Atacama.

Fig. 2. General geomorphological map of the Atacama ergs. 
frente al erg norte y $100 \mathrm{~m}$ frente al $\mathrm{erg}$ sur. Pero, hacia el interior, las dunas más cercanas están bien separadas de ellas, a distancias de 2 y $15 \mathrm{~km}$ respectivamente. Desde su extremo de barlovento, los mares de arena se desarrollan entre $\sim 300$ y $1200 \mathrm{~m}$ de altitud, por una distancia de $\sim 40$ y $30 \mathrm{~km}$ para los sistemas norte y sur correspondientemente. La gradiente media entre sus extremos proximal y distal puede ser de $\sim 23$ a $30 \mathrm{mkm}$ 1 (pendiente media entre 1.3 y $1.7^{\circ}$ ), pero la existente en el fondo de las cuencas varía entre 36 y $85 \mathrm{mkm}-1$ (pendiente media entre 2.1 y $4.9^{\circ}$ ). Cerca de la divisoria oriental de cada cuenca, el sistema dunar ha ascendido por pendientes entre 10 y $15^{\circ}$, hasta $\sim 1200$ $m$ de altitud. La superficie total de los ergs es $\left(240 \mathrm{~km}^{2}\right.$, de los que ( 158 corresponden al sistema norte y $(82$, al sistema sur. El conjunto forma la mayor superficie dunar conocida en Chile.

\section{Principios de clasificación}

La descripción de los mares de dunas se hará usando una clasificación de sistemas dunares interactuantes con las formas del relieve, considerando las dunas individuales sólo por su modo asociaciación entre si (Fig. 2). Este principio puede deducirse del análisis de patrones dunares diferenciados por el tipo de dunas, su espaciamiento y orientación, hecho en Australia (WASSON et al. 1988), o a partir de la asociación entre valles y dunas lineales ligadas al suministro de arena y al régimen de vientos practicada en el Kalahari (BULLARD \& NASH 1998). Determinaciones de edad de estos sistemas, especialmente con luminiscencia ópticamente estimulada (OSL) están permitiendo una más clara comprensión de su desarrollo (p. ej. STOKES et al. 1997a). A pesar de esto, no se llega todavía a un sistema taxonómico coherente para la denominación de sistemas, especialmente donde obstrucciones topográficas interactuan con el viento. Por esto, se define y fundamenta a continuación algunas de las categorías usadas en este trabajo (Fig. 2). En principio, la tradicional noción de «duna transversal», referente sólo a su orientación con respecto al viento, parece algo ambigua frente a los conocimientos genéticos actuales. VERSTAPPEN (1972) describe en el Desierto de Thar dos tipos de duna transversal: con elementos parabólicos, cuyos brazos en los extremos apuntan a barlovento y con rasgos barjánicos, cuyos cuernos en los extremos lo hacen a sotavento. Las primeras han sido llamadas transgresivas en Australia (BIRD 1984). Como para las segundas tiende a mantenerse la denominación de transversal, se propone denominar transverso-transgresivas a las dunas de un sistema compuesto por un elemento transversal barjánico y otro transversal parabólico. Estas dunas son tratadas como transversales por MOMIJI \& WARREN (2000), quienes distinguen en ellas dos elementos relacionados con su sinuosidad: alto barjanoideo y bajo lingüiforme (linguoid de COOKE et al. 1993). El modelo de migración de estos autores no explica por qué el patrón barjanoideo-linguiiforme mantiene la forma durante la migración, ya que la celeridad de la parte barjanoidea es mayor que en el modelo y la de sección lingüiforme es menor que en él, según deducciones de HOWARD et al. (1978). Por su parte, la categoría aklé es tratada aquí según la definición de sus autores, COOKE \& WARREN (1973). Su morfología corresponde al campo de dunas transgresivo de HESP et al. (1989). Pero es frecuente que posea rasgos de campo de dunas parabólicas imbricadas (HESP et al. 1989), con elementos traslapados y cordones rezagados (trailing ridges) usualmente cortos, cuencas de deflación ovoidales y dunas anidadas (nested). En éstas, el nido está compuesto por elementos parabólicos y barjánicos que lo cierran, por lo que es un rasgo esencialmente reverso. No obstante, esta estructura se puede dar tanto en valles y portezuelos como en cuencas más amplias. Para el primer caso se propone la denominación cinturón aklé («cinturón» en el sentido de belt de BAGNOLD 1984); para el segundo, la de cono de expansión aklé o sistema en forma de deyección de arena, organizada en estructura aklé donde la masa arenosa se expande en una depresión amplia, a sotavento de un cinturón dunar 


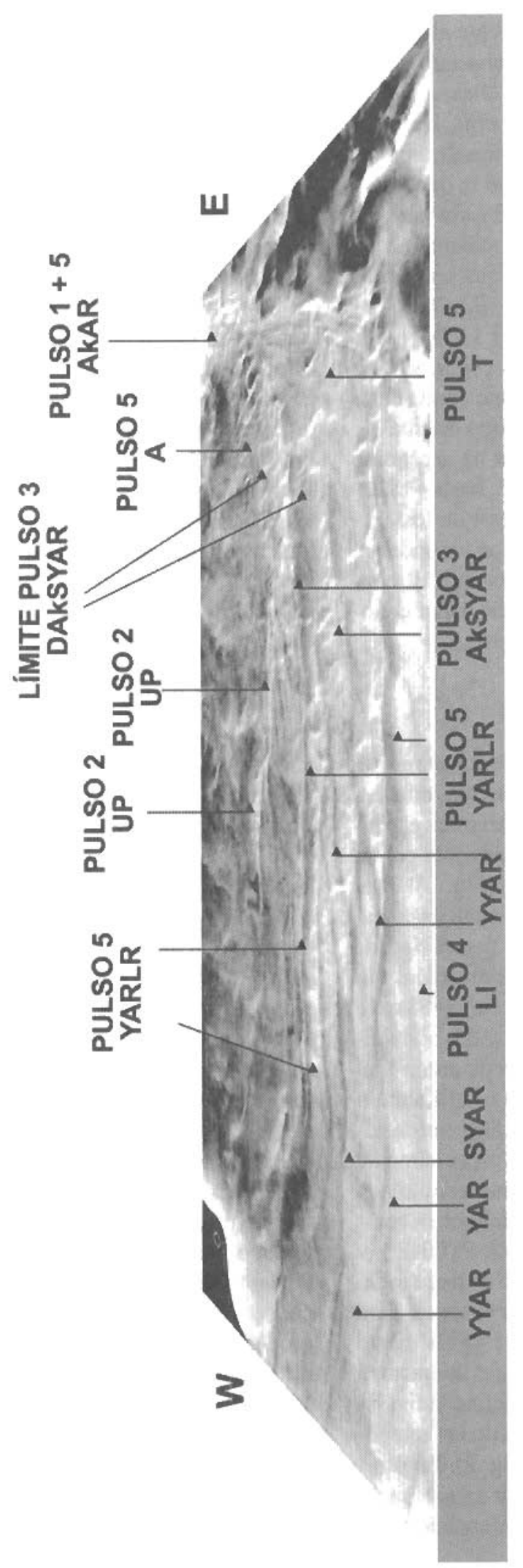

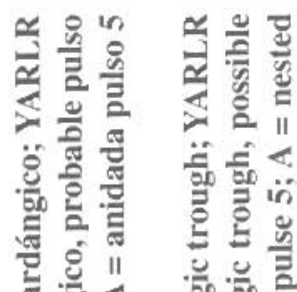

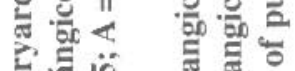

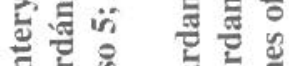

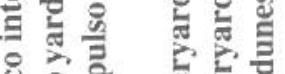
\& कै ㅍํ류 पूँ \%ाI

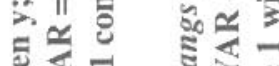

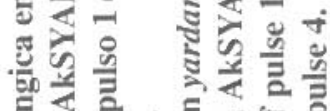

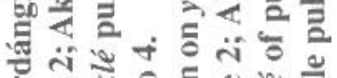

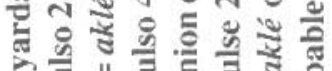

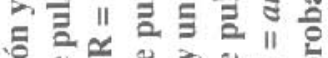
은

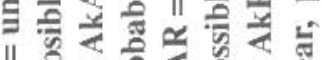

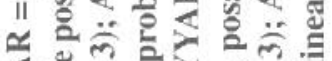

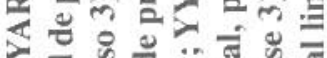

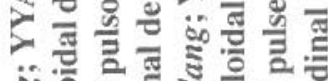

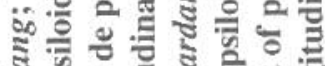

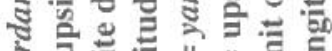

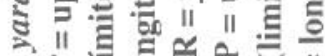

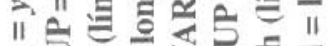

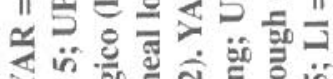
$>$ 을 งิ

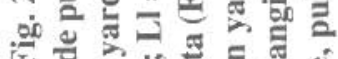
บำำ

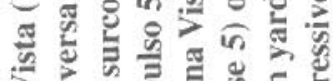

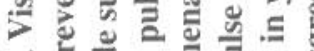

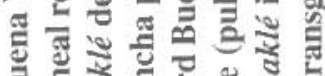

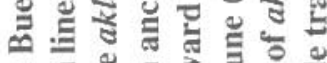

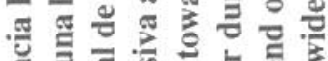

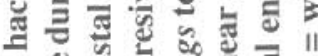
约 늠 초ำ

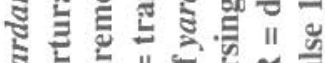

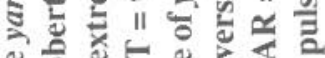
ๆ

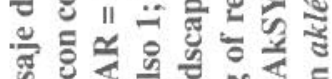

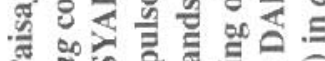
ป ะี कृ 
de valle estrecho. Aún más, tanto cinturones como conos de expansión pueden estar asociados con dunas parabólicas, transgresivas, transversales, barjanoides o reversas. En estos casos, se propone denominaciones compuestas, por ejemplo cinturón transverso aklé; el elemento asociado no es parte necesaria del aklé.

Para dunas referidas a barreras topográficas, TINLEY (1985) propone dos categorías: ascendente-descendentes (climbing-falling), las que raramente pueden constituir sistemas migratorios, y dunas de derivación (bypass). Entre ellas puede encontrarse formas transicionales. Ambas se dan como cinturones. Su tratamiento puede interferir con el de dunas lineales, porque éstas suelen conformar cinturones. El término lineal es actualmente preferido a «longitudinal» $\mathrm{u}$ otros, porque permite describir características morfológicas, sin interferir con la orientación relativa a los vientos formativos (BULLARD et al. 1995). TINLEY (1985) observó en Sudáfrica lineales simples, con crestas estrechas singulares o bifurcadas, y lineales com- puestas y complejas, con amplia zona de crestas barjanoideas, cuyas vertientes de precipitación alternan a ambos lados (pueden incluir formas estrelladas). Estas categorías equivalen a las lineales de cresta angosta (con horquillas en y escasas) y las lineales de cresta ancha (con elementos compuestos) de WASSON et al. (1988). Para el primer caso, la expresión duna longitudinal puede ser apropiada si se demuestra su longitudinalización a partir de dunas parabólicas, como fue observado por VERSTAPPEN (1968) en Pakistán y por ARAYA-VERGARA (1987) en Chile Central, donde no operan barreras topográficas.

\section{Observación de gabinete}

La estructura de los mares de dunas fue observada en fotos aéreas 1: 70000 de dos generaciones distintas: 1955 y 1997. La representación de conjunto se logró con un mosaico de las fotos de la última generación, el cual fue observado en pantalla de computador, estudiando ampliaciones de escena con procesamiento de imágenes. Estas escalas son

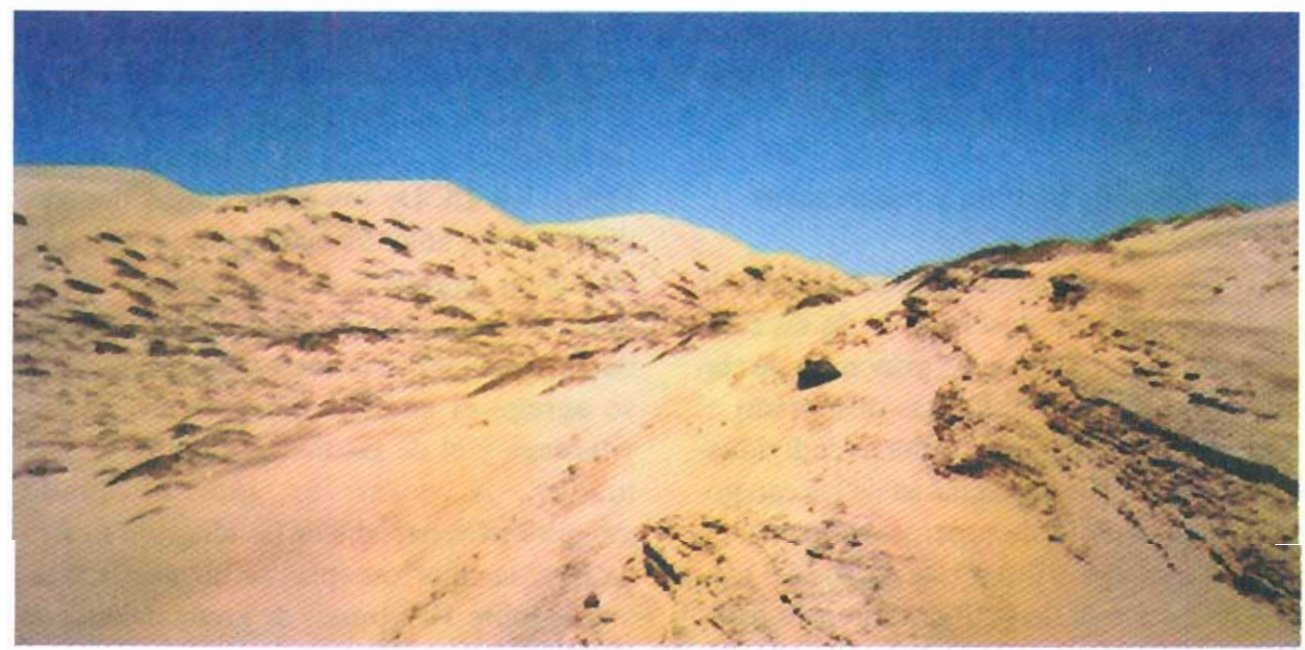

Fig. 4. Mar de Dunas Bajo Norte. Buena Vista (Figs. 2 y 3). Yardangs y surco interyardángico vistos hacia sotavento. Afloramiento de las areniscas del cuerpo yardángico, buzando hacia el Sur. Diferencia de pulso entre las dunas de fondo de surco y las lineales reversas de cresta de yardang.

Fig. 4. Northern Low Sea of Sand. Buena Vista (Figs. 2 and 3). Sight toward the lee: yardands and trough. Outcrop of sandstones of the yardangic slope, dipping southward. Difference of pulse between the dunes of trough bottom and the reversing linear of crest of yardang. 


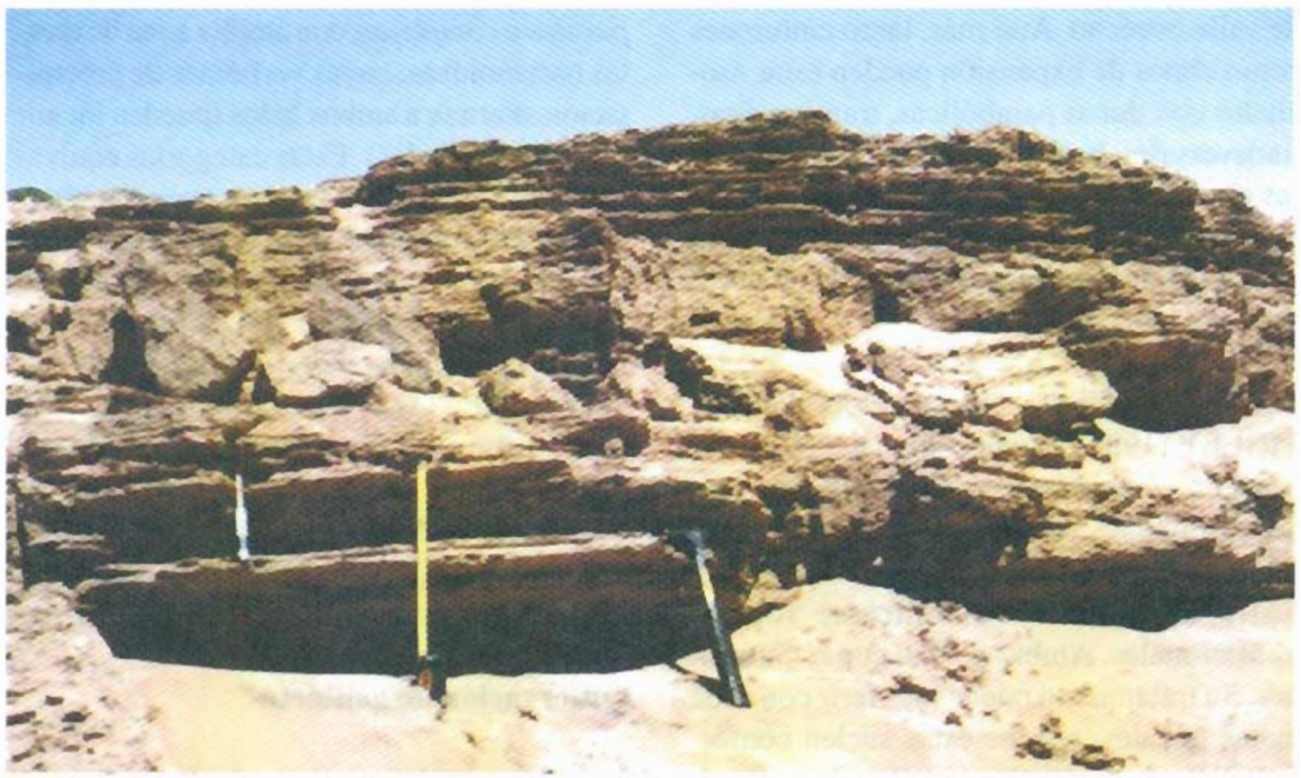

Fig. 5. Mar de Dunas Bajo Norte. Buena Vista (Figs, 2 y 3). Areniscas de cordón de yardang, vistas de $\mathrm{N}$ a S, en la dirección del buzamiento. Vertiente inversa (ver Tabla 1 y texto).

Fig. 5. Northern Low Sea of Sands. Buena Vista (Figs. 2 and 3). Sandstones of yardang ridge as seen from $\mathrm{N}$ to $\mathrm{S}$ in the dipping direction. Inverse slope (Table 1 and text).

suficientes para la parte morfológica y algunos aspectos de las fases evolutivas, pero no permiten discriminar las dunas vegetacionadas de las desnudas.

\section{Observación de terreno y laboratorio}

Esta observación fue dirigida a cada una de las asociaciones representativas de las categorías relatadas al tratar los principios de clasificación de sistemas. Fue observado el modo de asociación de las dunas individuales, las relaciones de vecindad de las categorías y la modalidad de superposición cuando ellas corresponen a diferentes pulsos del proceso formativo del erg. El criterio para reconocer el pulso presente con respecto a los pasados fue la ausencia o presencia de vegetación, vertiente de precipitación y ripples.

Las muestras de arena fueron tomadas en el Erg Norte, porque su extremo de barlovento está más cerca de las playas deflacionadas más antiguas, el Mar de Dunas Bajo está esencialmente sobre yardangs asociados también al litoral antiguo y existe un sistema dunar vecino a la playa actual de Ramadas (Figs. 1 y 2), cuya arena se puede contrastar con la de los pulsos antiguos. Con ellas se estudió las variables indicadas en la Tabla 1 y en las Figs. 11 a 15. De los cinco pulsos dunares distinguidos, sólo tres están representados en el análisis, porque la campaña de terreno no indicó con claridad, originalmente, la individualidad de los dos primeros pulsos. Además, se agrega el análisis del material de los yardangs y el de las dunas litorales de $\mathrm{Ra}-$ madas. A pesar de que el grado granulométrico modal de las muestras es arena fina, la morfoscopía se hizo principalmente sobre 100 granos de arena media por muestra, asumiendo que ésta refleja mejor el trabajo de los agentes operantes sobre el conjunto sedimentario. La revisión de porciones similares de arena fina, indica que la arena media representa bien a la muestra. La forma de los granos se determinó con el sistema ilustrado por POWERS (1953, en KRUMBEIN \& SLOSS 1969), debido a su confiable grado de objetividad. Pero la falta 
de correlación lineal entre esfericidad y redondez, indujo a analizar el desgaste sólo sobre la base de esta última. La revisión de arena media y fina indicó que las variables de textura superficial mostradas en la Tabla 1 eran los mejores índices para seguir la historia de las arenas.

\section{RESULTADOS}

Como referencia general de los fenómenos observados en los mares de arena, un mapa de síntesis (Fig. 2) indica su morfología, estructurada en sistemas de cuencas y sistemas referidos a barreras topográficas.

\section{Análisis de los mares de dunas y geosinergias asociadas}

\section{Erg (Sistema) Norte}

Mar de Dunas Bajo y Medio Norte (Figs. 2, $3 y 6)$

\section{Terrenos de deflación (no dunares)}

El espacio que media entre las playas antiguas deflacionadas sobre las terrazas marinas y los extremos de barlovento del erg (Figs. 1 y 2) puede identificarse como superficie de deflación. Representa el lecho del flujo migratorio de arenas dunares desde la costa hacia el interior, puesto que las dunas del extremo de barlovento del erg son secundarias, altamente evolucionadas. Por lo tanto, ellas deben haberse desplazado por distancias importantes de W a E, como lo demuestran sus rasgos morfológicos relatados más adelante.

Las superficies de glacis coluviales visibles son escasas. En los casos mejor expuestos y en las vertientes inmediatas puede encontrarse regs (Figs. 2), comunmente vegetacionados con cobertura de estepa, en la que las plantas principales pueden estar asociadas con nebkas, como ocurre al $\mathrm{N}$ de Sierra de la Gloria, entre los mares de dunas Bajo y Medio.

Infrayaciendo a las dunas, se encuentra un conjunto de cordones y surcos paralelos a la dirección del viento formativo del mar de arenas (Figs. 2 y 3 ). La profundidad de excavación de los surcos es de orden decamétrico (Fig. 4), sobre areniscas blandas estratificadas en capas laminares de espesor centimétrico (Fig. 5). La consistencia de éstas es mayor que $4.5 \mathrm{kgcm}^{2}-1$ (por penetrometría en seco), valor que baja en los planos de estratificación (comunmente a no menos de 3). Pero su friabilidad en la escala de Ollier es avanzada (4-5), puesto que los terrones pueden ser quebrados con la mano. La longitud de los dorsos puede ser de $\sim 10$ $\mathrm{km}$ con una separación entre crestas que promedia los $250 \mathrm{~m}$. Estos rasgos son característicos de los yardangs. Los cordones no son totalmente paralelos y se abren en abanico cerrado inducidos por los valles preexistentes. En el sector norte (Buena Vista), las crestas son agudas y levemente curvadas. En su mitad proximal (4 a $5 \mathrm{~km}$ ) tienen poco revestimiento dunar o arenoso, pero en la distal están recubiertos por más de una generación o pulso dunar con formas que se densifican crecientemente hacia el E. En el borde sur, las crestas son más redondeadas y rectilíneas. Las capas de areniscas buzan entre 18 y $25^{\circ} \mathrm{S}$ y la dirección del sistema de surcos y cordones es aproximadamente WE. Por lo tanto, en perfil transversal, estos yardangs son monoclinales.

\section{Terrenos dunares}

Este sistema sobreyace a los paisajes de regs y de yardangs en el valle Los Corralillos (Fig. 2). En los mares de dunas Medio y Bajo están representados esencialmente cinco pulsos formativos (Figs. 3 a 10):

Pulso 1: Estas dunas se extienden inmediatamente al $\mathrm{N}$ de la Sa. de la Gloria (Figs. 2, 3,6 y 7). El sistema es aklé con un fuerte componente transversal. En su mayoría son formas suaves y vegetacionadas (estepa), indicando un conjunto generalmente inactivo. Se trata de dunas transverso-transgresivas muy comprimidas. Desde $\sim 600$ a $1000 \mathrm{~m}$ de altitud hay gradación morfológica debido al efecto topográfico de ascenso, apareciendo un patrón de dunas macizas de estructura aklé 


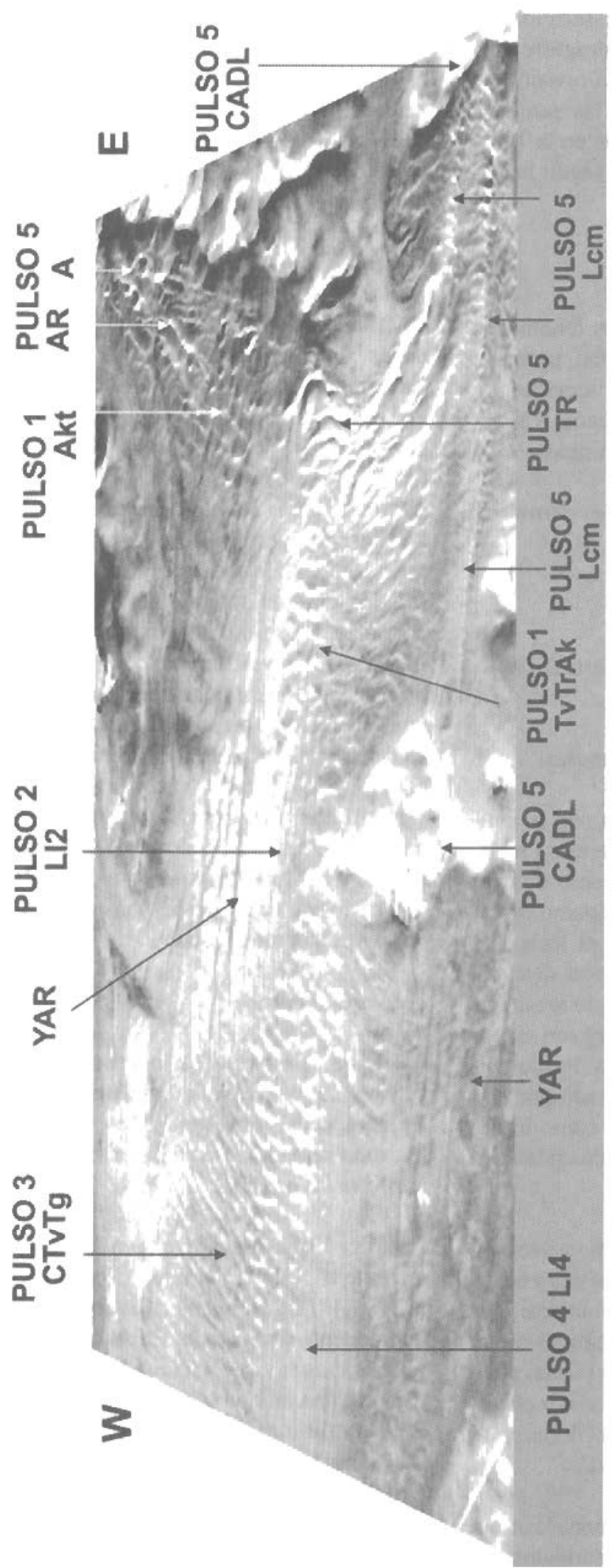

ฮั 解记 나을

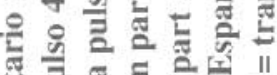
흘

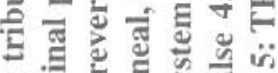

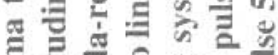

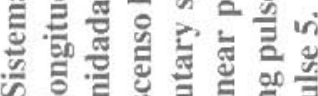

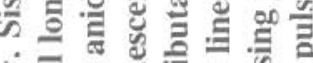

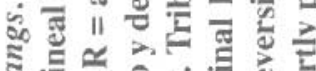

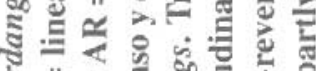
"I in

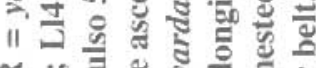

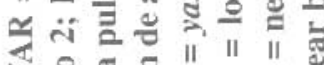

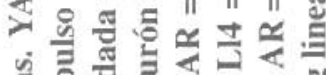

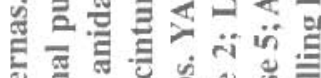
跣

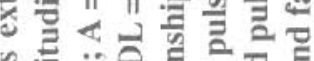

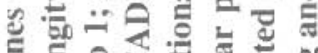

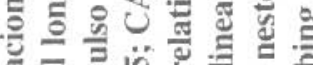

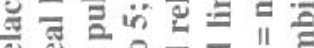

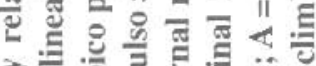
- II

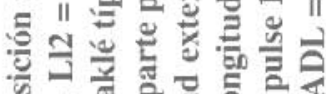

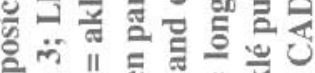

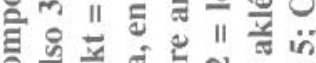

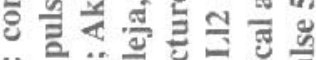

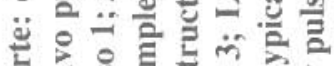

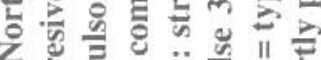

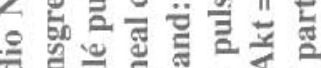

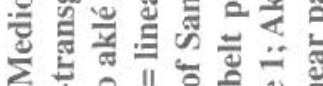

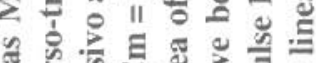

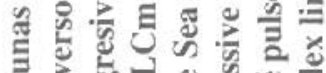

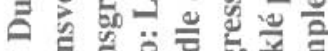
을 혼

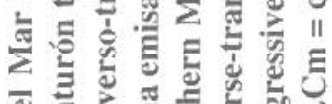

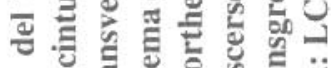
II

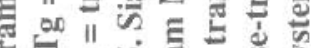
的的 II

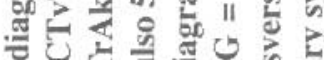
i.

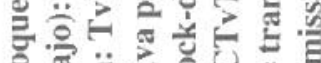

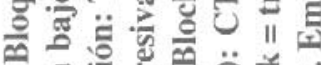
․․ำ

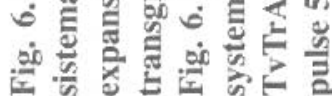




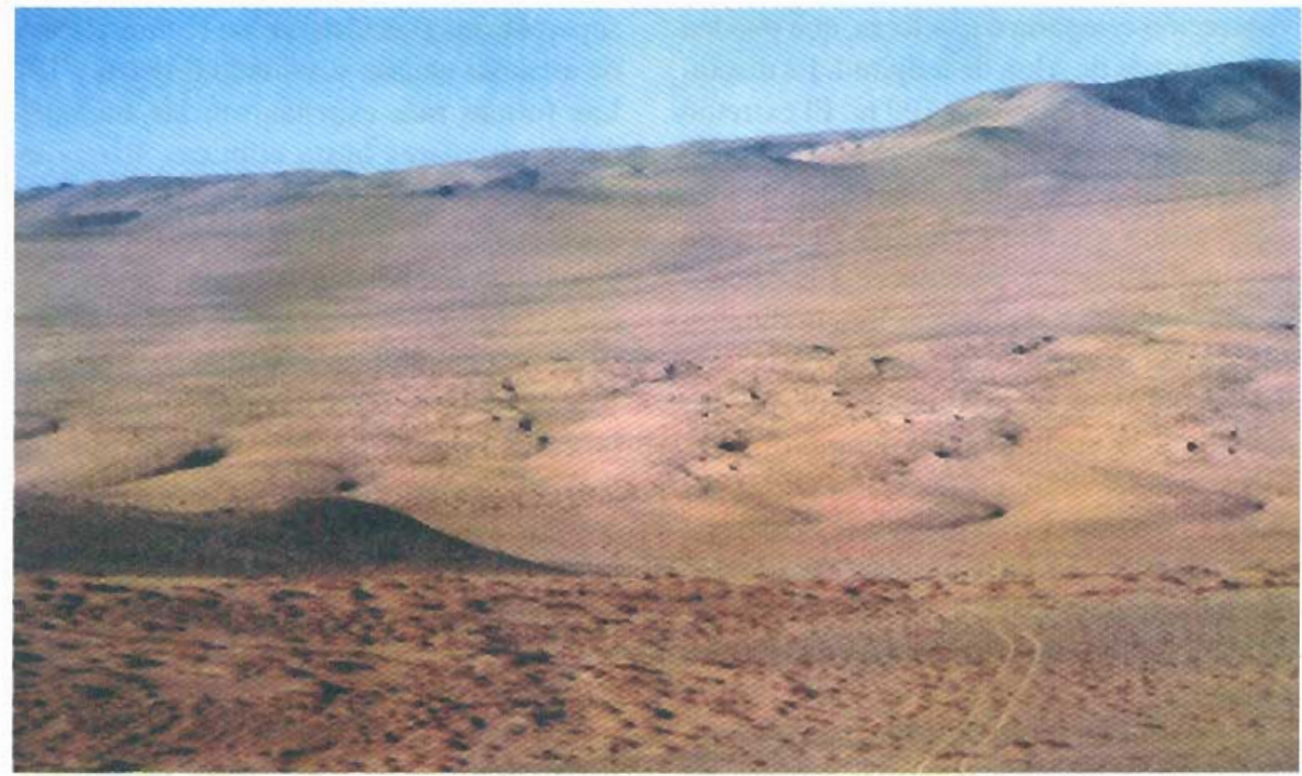

Fig. 7. Mar de Dunas Bajo a Medio Norte. Sistema transverso-transgresivo aklé, pulso 1 (Fig. 6). A la derecha de cada duna, vertiente de sotavento inactiva. Formas vegetacionadas con estepa baja.

Fig. 7. Northern Low-Middle Sea of Sand. Transverse-transgressive-aklé system, pulse 1(Fig. 6). At right of each dune, inactive lee slope. Vegetated landforms with low steppe.

más comprimida en el extremo de sotavento. En la cuenca alta que enfrenta al $\mathrm{C}^{\circ} \mathrm{del} \mathrm{Al}$ garrobo el patrón es aklé parabólico, con distintos grados de compresión.

Pulso 2: Sobreyaciendo al conjunto transverso-transgresivo aklé de la parte baja se desarrolla un sistema de dunas lineales simples de longitud kilométrica y $100 \mathrm{~m}$ de distancia promedio entre ellas (Fig. 6). Son paralelas entre si, presentando un "corduroy pattern" o patrón en côtelé, por su aspecto parecido al de la tela de este nombre, que simula cordones paralelos. Su sector proximal está parcialmente cubierto por las dunas del pulso 3 , siendo visibles sólo 2 a $3 \mathrm{~km}$ de su longitud total. A pesar de esta limitación observacional, puede denominárseles longitudinales por ser simples y alcanzar a mostrar al menos un elemento en y. Su modelado es suave y también están cubiertas por vegetación esteparia.

Pulso 3: Está constituido por dunas de disposición transversal que, yuxtapuestas, recubren el extremo proximal de las dunas longitudinales del pulso 2 (Fig. 6). La longitud de los cordones es variable, $\sim 200 \mathrm{~m}-2$ $\mathrm{km}$; la longitud de onda promedia $\sim 200 \mathrm{~m}$; en planta, son formas onduladas, convexas y cóncavas a barlovento, con extremos de estilos tanto barjánico como parabólico; por esta razón, el sistema es denominado cinturón transverso-transgresivo. Sus formas son suaves, con vegetación de estepa e inactivas. En la parte proximal las dunas son típicamente parabólicas (en U), por lo que el carácter transverso transgresivo es adquirido en función de la distancia al extremo de barlovento (Fig. 9).

Pulso 4: Está representado por un sistema de dunas lineales claramente suprayacente al sistema transverso transgresivo del pulso 3 (Figs. 6, 8 y 9). Su aspecto «corduroy» (côtelé) es similar al de las longitudinales del pulso 2 ; también pueden denominarse longitudinales, porque presentan uniones en $\mathrm{y}$ asociadas a formas upsiloidales, lo que indica que se originaron por alargamiento de parabólicas. Se trata de formas suaves, con 
vegetación esteparia e inactivas, que pueden alcanzar más de $4 \mathrm{~km}$ de longitud. La distancia media entre ellas es $\sim 100 \mathrm{~m}$. El extremo de barlovento es un poco más proximal que el del pulso 3 y contiene dunas upsiloidades que, como primera manifestación de longitudinalización, pertenecen a la categoría más cercana a las lineales longitudinales, conformando una misma familia. Formas en y cerca del extremo proximal indican el paso paulatino de upsiloidales a longitudinales. Estos hechos sugieren que el material del pulso 4 fue suministrado a barlovento del sistema del pulso 3 y no a expensas de éste. No hay indicaciones claras de un pulso más reciente a barlovento. Los restos de cordones de playa antiguos más cercanos están a $\sim 2$ km hacia la costa (Fig. 9). En el espacio intermedio hay unas pocas formas parabólicas aisladas, asociables al pulso 4 .

Pulso 5: Se trata del pulso presente. Tiene representación notoria en las cuencas altas cerca de la divisoria del extremo distal del pulso 1 , a alturas cercanas a los $1000 \mathrm{~m}$. Frente al $\mathrm{C}^{\circ}$ del Algarrobo (Fig.2) hay dos estilos superpuestos al aklé del pulso 1: transgresivo de escamas anchas y anidado (Figs. 6 y 10). Las formas más esbeltas son las anidadas, desde circulares hasta elípticas alargadas. Más al S, cerca de Sa. de la Gloria, el estilo superpuesto es transgresivo, con unidades bien transversalizadas y algunas formas anidadas (Fig. 10). Ambos estilos sustentan vertientes de precipitación activas y carecen de vegetación. Las dunas anidadas resultan de la composición compleja de elementos barjánicos y parabólicos, lo que se asocia con crestas reversas, indicando variabilidad importante del viento local. Este tipo de crestas también existe en las estribaciones sur de las grandes transgresivas cercanas a Sa. De la Gloria. En ambos casos hay evidencias de vientos en sentidos opuestos. Pero también existe reactivación de dunas transversotransgresivas más bajas, al N de Sa.de la Gloria, expresadas en dunas barjánicas superpuestas.

Pulsos asociados a los yardangs: Es posible distinguir hasta tres pulsos asociados a los yardangs al interior de Pampa Caracoles-

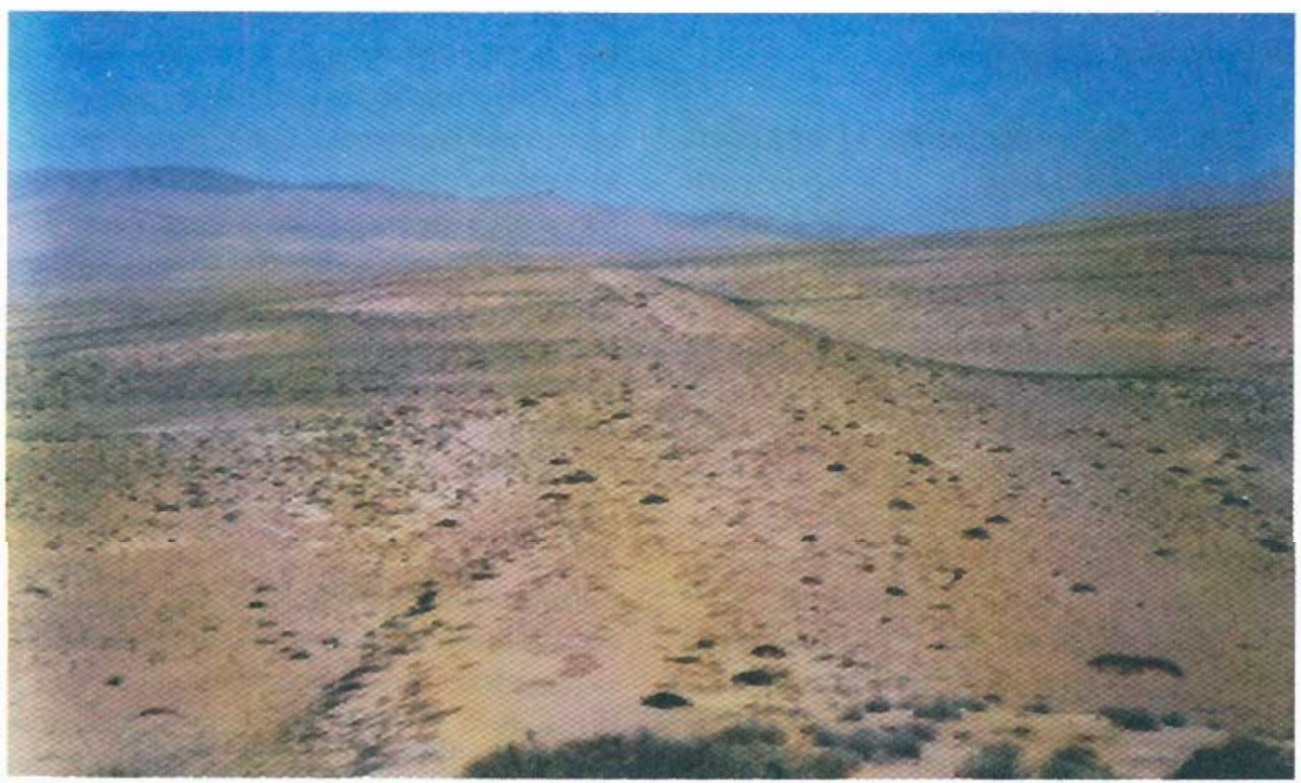

Fig. 8. Mar de Dunas Bajo Norte. Cinturón transverso-transgresivo pulso 3 recubierto por sistema lineal longitudinal pulso 4 . Ambos sistemas son vegetacionados e inactivos. Fug. 8. Northern Low Sea of Sand. Transverse-transgressive belt, pulse 3 overlayed by longitudinal linear system of pulse 4 . Both systems are vegetated and inactive. 
Buena Vista (Figs. 2, 3 y 4). Por su emplazamiento, el más distal parece corresponder al pulso 1, aklé, de cuenca alta; morfológicamente, es similar a su homólogo que enfrenta a $\mathrm{C}^{\circ}$ del Algarrobo. En la parte baja, su correspondiente parece ser un modelado suave y camuflado de dunas parabólicas de asociación aklé. Después hay un grupo dunar que cubre la mayor parte de los yardangs, compuesto principalmente de dunas upsiloidales y sus productos longitudinales, con dirección parecida a la de los dorsos yardángicos, pero algo desviada con respecto a éstos. Este grupo es vegetacionado y estable; debe estar entre los pulsos 2 y 3 . Uniones en y del diseño upsiloidal pueden observarse tanto en los surcos como haciendo juego con las crestas yardángicas. En los surcos hay extructuras aklé confinadas a cada uno, de un pulso más reciente, al parecer 3. Finalmente, el grupo del pulso 5 aparece tanto alterando morfológicamente los elementos del pulso 1 de cuenca alta, con formas anidadas y reversas, como en las cimas yardángicas. En este caso, toma la forma de dunas lineales superpuestas a los yardangs, con elementos parabólicos, barjanoideos y crestas reversas, con vertientes de precipitación alternadas en lados opuestos (Fig. 4). Esto indica influencia de vientos variables en su desarrollo.

\section{Características de las arenas}

Las arenas de los diferentes pulsos son parecidas (Tabla 1). Su grado granulométrico modal es arena fina. Su color es difícilmente diferenciable; refleja una generalizada oxidación del material. Éste está compuesto esencialmente por vidrios volcánicos claros, cuarzos y fragmentos de concha, a los que se suma una cantidad menor de ferromagnesianos, que pueden ser líticos. Los cuarzos están generalmente oxidados y su proporción determina la gradación de los tonos pardos del conjunto arenoso. Los vidrios volcánicos son silícicos, con pocos individuos oxidados. Los fragmentos de concha también presentan poca oxidación. Globalmente, la redondez de los granos es relativamente baja. Predominan los subangulosos, pero también hay muchos granos pulidos sobre distintos grados de redondez, que - en proporción notoria - pueden estar además oxidados. Si se considera los conjuntos litológicos por separado (Figs. 11 a 15), los vidrios muestran la redondez más baja; son mayoritariamente subangulosos, pero con esquinas frecuentemente pulidas. Una menor parte está oxidada y pulida. Redondez menos baja presentan los cuarzos, siempre con predominio de granos subangulosos, pero con aumento de ejemplares subredondeados a redondeados, en gran parte oxidados y pulidos. No se encuentra casos claros de granos deslustrados por abrasión. La mayor redondez se ve en los fragmentos de concha, con cantidades importantes de granos redondeados, de superficie lisa y pulida y algunos individuos oxidados.

Los granos de la arenisca de yardang (Fig. 11) son morfoscópicamente similares a los de las dunas, cohesionados por cemento calcáreo y - probablemente - ferruginoso. Se diferencian bien de los dunares por su mayor cantidad de fragmentos de concha, la mayor parte de los cuales presenta superficie rugosa, que indica corrosión. Algunos vidrios volcánicos calcificados sugieren precipitación de carbonato correlativa a la corrosión de los fragmentos de concha.

Estas características contrastan con el material de un sistema dunar vecino a la playa presente de Ramada, al $\mathrm{N}$ de Caldera (Fig. 1), que es blanco a gris claro, aunque su modo granulométrico también está en arena fina. En él están representados los mismos grupos petrográficos que en la dunas antiguas interiores, pero los vidrios volcánicos carecen de oxidación, los cuarzos muestran pocos individuos oxidados y los ferromagnesianos son más escasos. La proporción de arena biodetrítica (fragmentos de conchas) es alta, expresándose en casi $40 \%$ de calcáreo. La cantidad de granos pulidos es mucho menor que en las dunas interiores. La mayor parte del material es subanguloso (Fig. 15). El desgaste aumenta desde vidrios volcánicos a fragmentos de concha. Granos redondeados sólo aparecen en cuarzos y fragmentos de 
concha, con (4 y $10 \%$ respectivamente. La distribución de esta propiedad es parecida a la de las dunas interiores.

Comparando las arenas de los diferentes pulsos, incluida la arenisca de vertiente yardángica, se observa lo siguiente (Tabla 1 , Figs. 11 a 15):

Considerando que la arenisca yardángica es deposicionalmente más antigua que los pulsos dunares, llama la atención que su color sea más parecido al de las arenas de los pulsos 4 y 5 que al de las del pulso 3, que son las más oscuras, porque tienen la mayor cantidad de minerales ferromagnesianos (20\%). Mejor índice diferenciador entre pulsos es el contenido en calcáreo. Éste es mucho mayor en la arenisca de vertiente yardángica que en los pulsos dunares 3 a 5 . Entre estos últimos, su monto disminuye con la antigüedad del pulso.

Granulométricamente, la proporción de arena fina como grado modal es mayor en las dunas lineales de los pulsos 4 y 5 que en las transverso-transgresivas del pulso 3, lo que sugiere una mejor selección granulométrica en la construcción de las primeras, independientemente del pulso operante. La proporción más baja de arena fina en las transversotransgresivas es parecida a las de las areniscas yardángicas y de las dunas litorales de Ramadas. En todo caso, las areniscas presentan la menor cantidad de arena fina.

Desde el punto de vista litológico, las proporciones de vidrio volcánico y cuarzo no parecen ser indicadores de diferencias entre pulsos y ambientes de sedimentación. En cambio, los ferromagnesianos pueden estar directamente relacionados con el grosor de la arena de cada pulso, puesto que - existiendo en cantidades despreciables donde la arena fina es más abundante - aparecen en mayor número que los fragmentos de concha en las dunas transverso-transgresivas, que poseen arenas más gruesas (Fig. 14). Por su parte, la abundancia de fragmentos de concha es, obviamente, un buen indicador de diferencias en el mismo sentido que la proporción de calcáreo.

\section{Tabla 1: Características de las arenas del Erg Norte, Mar de Dunas Bajo y Medio}

\begin{tabular}{|c|c|c|c|c|c|c|c|}
\hline Forma muestreada & $\begin{array}{c}\text { Color de la } \\
\text { arena }\end{array}$ & $\begin{array}{c}\% \\
\text { calcáreo }\end{array}$ & $\begin{array}{l}\text { Grado modal, arena } \\
\text { fina, } 125-250 \mu, \%\end{array}$ & $\begin{array}{l}\text { Oxidados y } \\
\text { pulidos } \%\end{array}$ & $\begin{array}{l}\% \text { granos } \\
\text { oxidados }\end{array}$ & $\begin{array}{c}\% \text { granos } \\
\text { pulidos }\end{array}$ & $\begin{array}{c}\text { Superficie } \\
\text { biodetritos }\end{array}$ \\
\hline $\begin{array}{l}\text { Vertiente de yardang: } \\
\text { arenisca (capas } \\
\text { laminares) }\end{array}$ & $\begin{array}{l}\text { 10YR } 6 / 4 \text { pardo } \\
\text { amarillento claro }\end{array}$ & 26.2 & 53 & 53 & 39 & 31 & $\begin{array}{c}\text { Corroida } \\
83,9 \%\end{array}$ \\
\hline $\begin{array}{c}\text { Duna lineal } \\
\text { suprayacente a } \\
\text { yardang pulso } 5\end{array}$ & $\begin{array}{l}\text { 10YR } 6 / 4 \text { pardo } \\
\text { amarillento claro }\end{array}$ & 13.9 & 74 & 76 & 44 & 36 & $\begin{array}{l}\text { Pulida } 100 \% \\
\text { corroida } 19 \%\end{array}$ \\
\hline $\begin{array}{c}\text { Duna lineal } \\
\text { longitudinal pulso } 4\end{array}$ & $\begin{array}{l}\text { 10YR } 6 / 4 \text { pardo } \\
\text { amarillerito claro }\end{array}$ & 10.0 & 71.3 & 90 & 60 & 54 & Pulida $100 \%$ \\
\hline $\begin{array}{l}\text { Duna transverso } \\
\text { transgresiva pulso } 3\end{array}$ & $\begin{array}{l}\text { 10YR } 6 / 3 \\
\text { pardo pálido }\end{array}$ & 8.1 & 56.8 & 80 & 55 & 46 & \begin{tabular}{|} 
Pulida $100 \%$ \\
corroida $6.7 \%$
\end{tabular} \\
\hline $\begin{array}{c}\text { Dunas vecinas al litoral } \\
\text { presente }\end{array}$ & $\begin{array}{c}\text { 10YR } 8 / 17 / 1 \\
\text { blanco a gris } \\
\text { blanco }\end{array}$ & 39.7 & 57.4 & 62 & 18 & 11 & Pulida 47.4\% \\
\hline
\end{tabular}




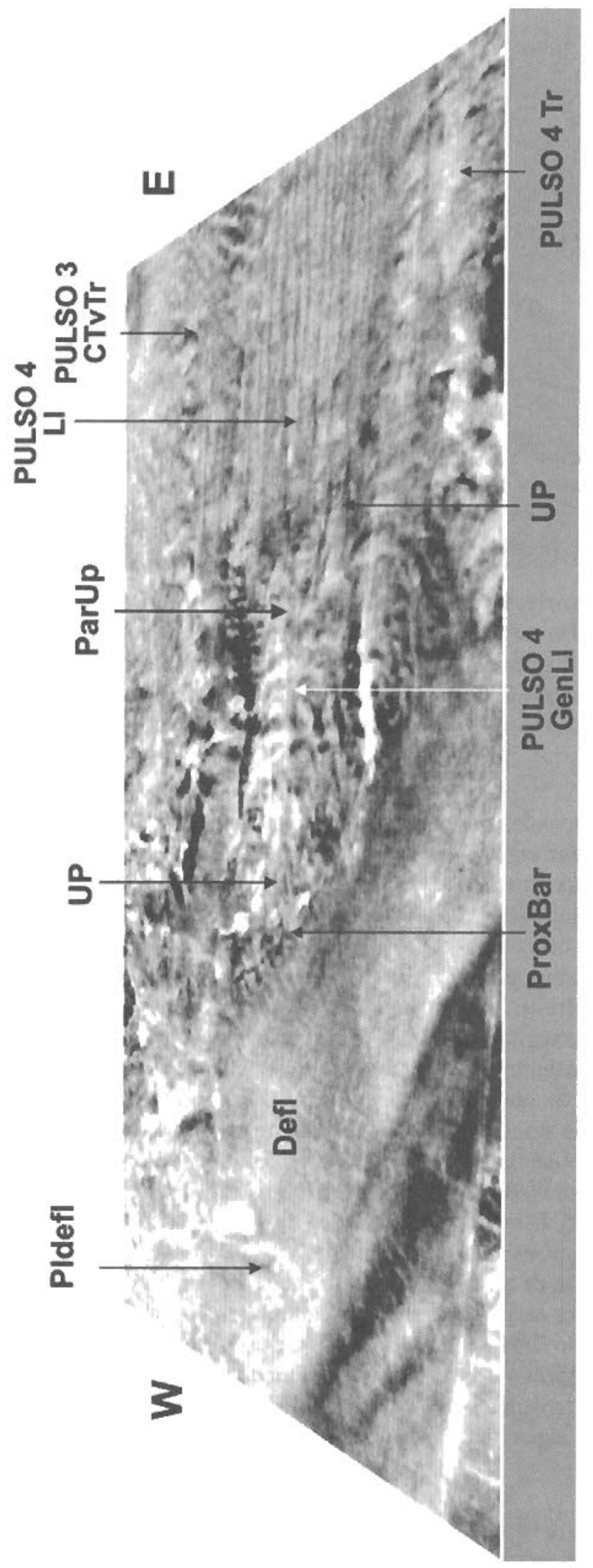

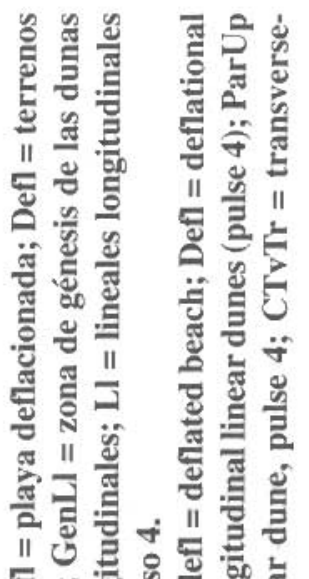

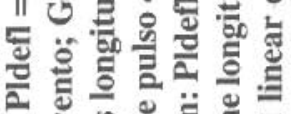

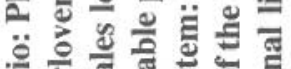

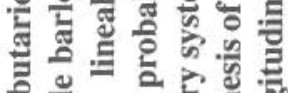

을 놀

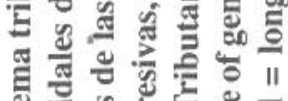

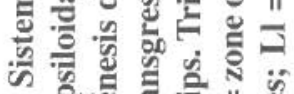

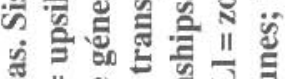

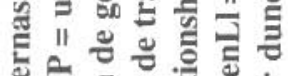

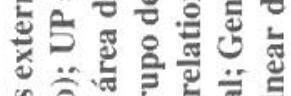

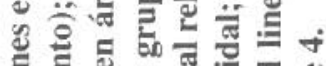

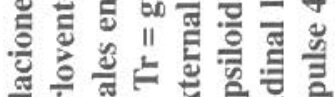

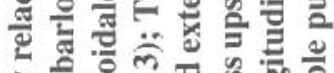

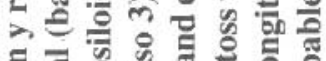

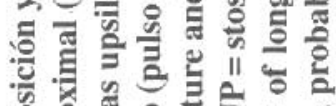

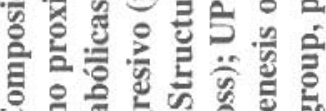

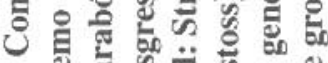

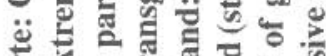

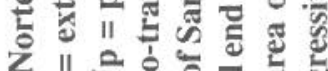

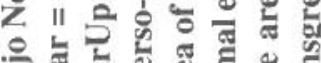

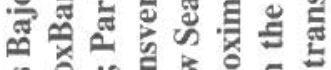

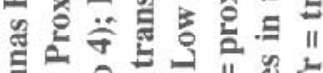

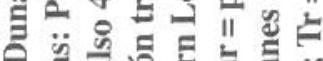

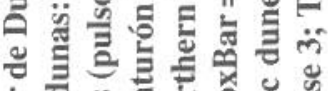

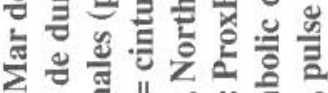

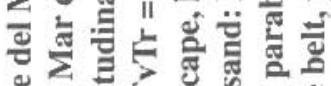

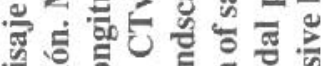

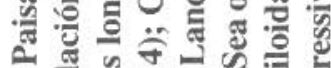

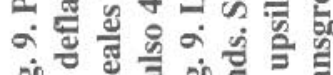

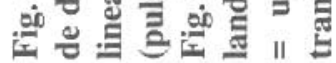




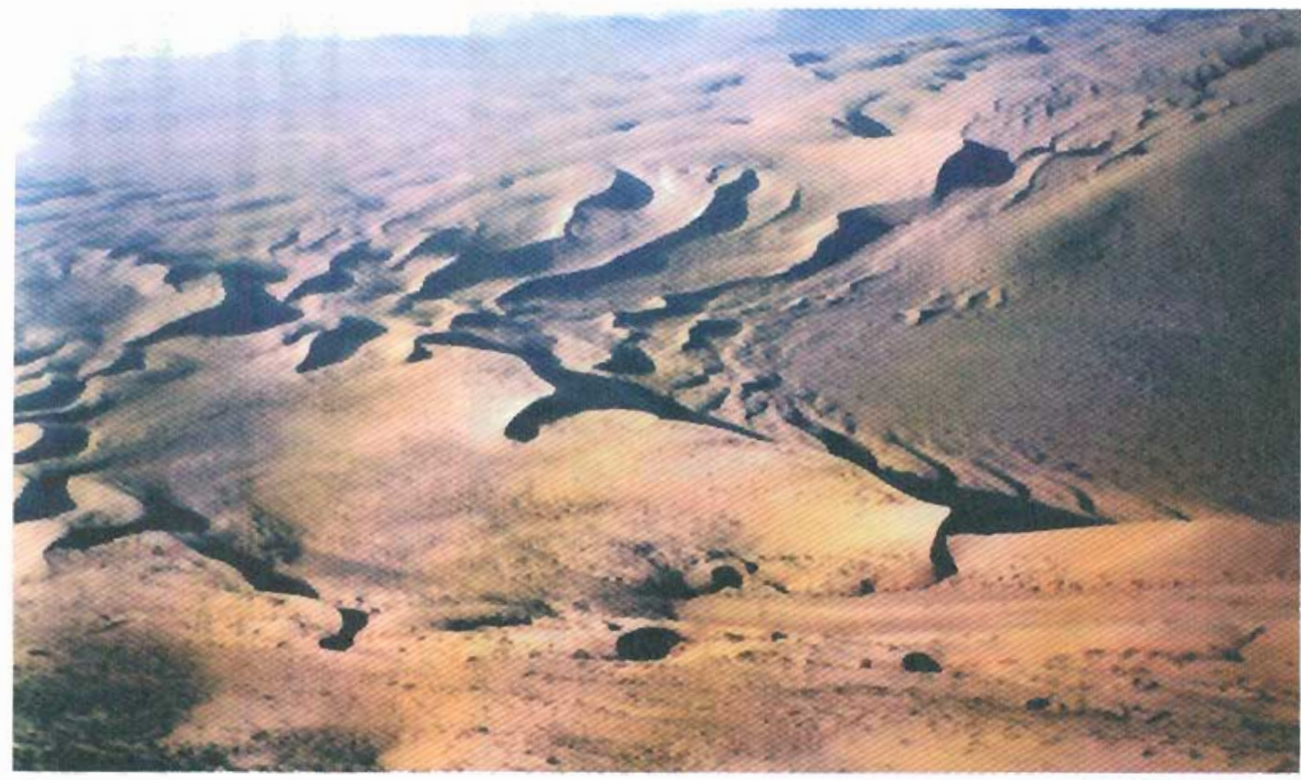

Fig. 10. Mar de Dunas Medio Norte. Parte distal del cono de expansión aklé. Al NW de Sa. de la Gloria (Figs. 2 y 6). Dunas transgrasivas distales pulso 5, con vertientes de precipitación activas y formas reversas.

Fig. 10. Northern Middle Sea of Sand. Distal part of the aklé expansion fan. NW of Sa. de La Gloria (Figs. 2 and 6). Distal transgressive dunes, pulse 5, with active precipitation slopes and reversing forms.

Relacionando la litología con la redondez, las distribuciones más parecidas se dan entre el material de yardang y el de las lineales reversas del pulso 5 que los sobreyacen (Figs. 11 y 12). Para vidrio volcánico y cuarzo, las curvas son monomodales, indicando entre 80 y más de $90 \%$ de granos subangulosos. Sólo en los yardangs hay algo de arena cuarzosa y volcanoclástica redondeada. En cambio, las distribuciones para fragmentos de concha tienden a ser bimodales. El modo principal muestra que la mayor parte del material es redondeado o subredondeado, sobre todo en el caso de la duna lineal del pulso 5. Esta distribución es algo diferente en los pulsos antiguos 4 y 3 , en los que una fracción de arena biodetrítica ( 30 a $40 \%$ ) alcanza los mayores grados de redondez. Para el pulso 3, el segundo lugar en desgaste to tienen los ferromagnesianos. Vidrios y cuarzos muestran un comportamiento menos específico para estos pulsos.

Observando la textura superficial, se encuentra que el monto de granos pulidos es menor en la arenisca de yardang y aumenta gradualmente con la edad de los pulsos dunares. La cantidad de granos oxidados también es menor en la arenisca yardángica, pero aumenta sólo hasta el pulso 4, para disminuir hacia el pulso 3. Similar tendencia se observa en el monto de granos oxidados y pulidos, aunque su número es siempre mayor en el pulso 3 que en el pulso 5. Es ilustrativo comparar la textura superficial de la arena biodetrítica. Mientras en los yardangs casi todo este material está corroido, en las dunas está liso y pulido, pero en las lineales del pulso 5 algo menos del $20 \%$ presenta corrosión previa al pulimiento y en las transverso-transgresivas del pulso 3 esto ocurre en una porción menor. En cambio, en las lineales del pulso 4 todas estas arenas son lisas y pulidas. En otras palabras, el grado de corrosión que muestran las arenas biodetríticas de los pulsos dunares parece ligado a su relación con ambientes abastecedores de material donde operó la corrosión de biodetritos. Las arenas de las dunas lineales del pulso 5 son parecidas a la de la arenisca yardángica tanto en redondez 


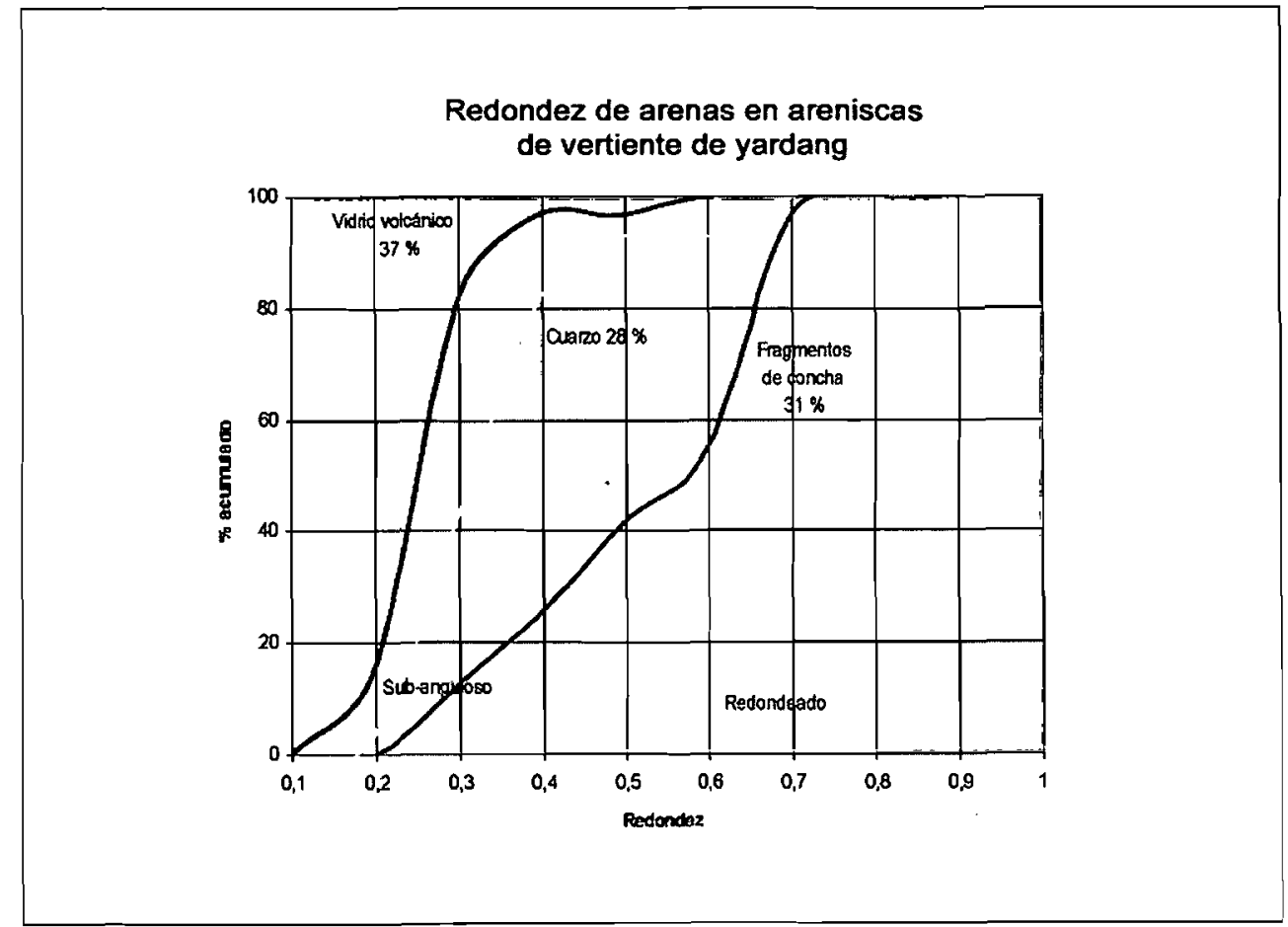

Fig. 11. Mar de Dunas Bajo Norte: arenisca de yardang.

Fig. 11. Northern Low Sea of Sand: sandstone of yardang.

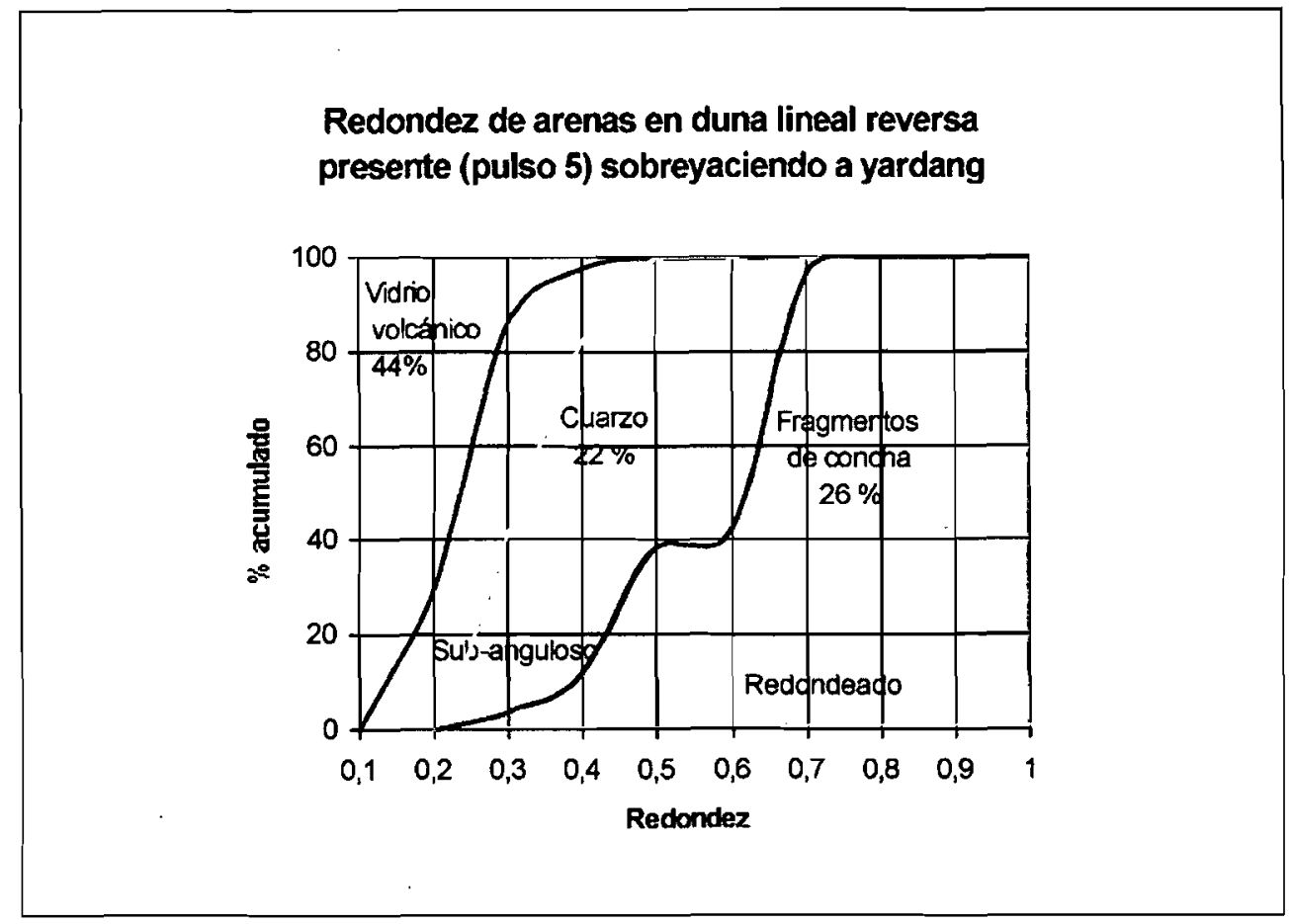

Fig. 12. Mar de Dunas Bajo Norte: pulso presente recubriendo a yardang.

Fig. 12. Northern Low Sea of Sand: present pulse overlaying a yardang. 
como en textura superficial, lo que sugiere que la segunda debe haber sido importante en abastecimiento de las primeras. En proporcion mucho menor, el material del pulso 3 también parece abastecido por ambientes de corrosión de biodetritos. En cambio, el del pulso 4 no sugiere relación con estos ambientes.

\section{Mar de Dunas Alto Norte}

Este mar se extiende a sotavento de los mares Bajo y Medio. Su enlace con ellos es mediante un cinturón ascendente-descenden$t e$, que a la vez es un sistema de dunas lineales compuestas. La secuencia formativa de este sistema es como sigue (Figs. 2 y 16):

Pulso 1: Este sistema se extiende al $\mathrm{N}$ de Minera Atacama. La parte expuesta es un derrame de masa hacia e] $\mathrm{E}$ del cono de ex- pansión aklé, a través del portezuelo ubicado frente a su eje, desde donde toma la forma de cinturón aklé. La formas son suaves, esencialmente inactivas y vegetacionadas. $\mathrm{La}$ longitud de onda entre las crestas de dunas transgresivas es mucho mayor que en el cono de expasión que recubre este pulso, en una relación de 2:1(ver Aktd, Fig. 16). Las dunas del pulso entran a ocupar el fondo del valle de sotavento, en común con el cinturón proveniente del Sur, debido a su confluencia al $\mathrm{N}$ de Minera Atacama. Pero ellas recubren por yuxtaposición a este cinturón, revelando su menor antigüedad. Hacia el $\mathrm{E}$, ambos cinturones se funden complejamente. Esta fusión muestra elementos parabólicos y barjánicos, generándose un anidamiento de tendencia poligonal, al parecer a causa de vientos variables que alinean las crestas de nidos en segmentos rectilíneos (Fig. 16, a sotavento de YCAk).

\section{Redondez de arenas en dunas lineales longitudinales del pulso 4}

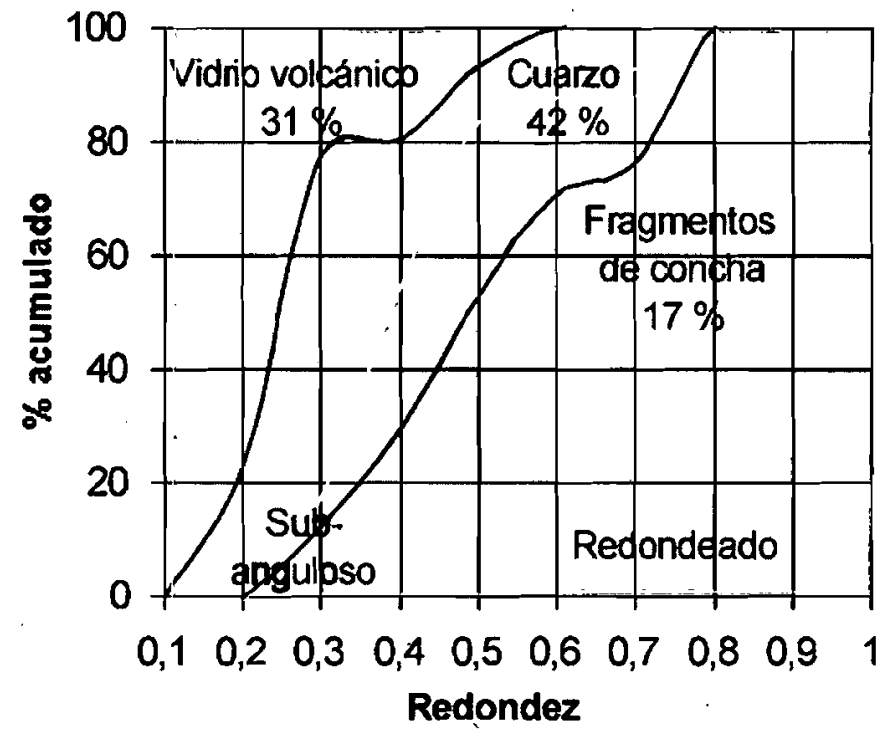

Fig. 13. Mar de Dunas BBajo Norte: último pulso formador de dunas estabilizadas. Fig. 13. Northern Low Sea of Sand: last pulse, formative of stabilized dunes. 
Pulso 2: Está representado esencialmente en el cono de expansión, como aklé típico, de menor longitud de onda con respecto al pulso 1 , en razón de $\sim 1: 2$, indicando compresión del aklé. La masa fundamental es inactiva, con formas suaves y colonizadas por estepa baja (Figs. 16 y 17). El cono se abre desde el sistema tributario como continuación de una duna lineal compleja de crestas parabólicas, atribuida por lo tanto al mismo pulso 2.En la parte más alta del cono de expansión hay reactivaciones del pulso 5 .

Pulso 3: Está representado por una duna lineal compleja, suprayacente a la del pulso 2 (Fig. 16). Se trata de un sistema más angosto, cuyas crestas indican mayor compresión. Penetra en forma de punta de lanza sobreyaciendo al aklé del cono de expansión, razón por la que es denominada lineal compleja inyectada.

Pulso 5: A barlovento, el pulso presente está en el sistema tributario (Fig. 16), expresado en una duna lineal compleja. La parte denominada La Ballena (Figs. 2 y 18) es sólo parcialmente activa. En su segmento más característico, las vertientes presentan ondulaciones de pequeña longitud de onda $(\sim 30 \mathrm{~m})$, con crestas en la dirección de la pendiente. Observaciones en la línea de crestas de la divisoria principal, indican microformas con crestas barjánicas y parabólicas, proyectadas como brazos y cuernos alargados a través de la vertiente, lo que explica la micro-ondulación. El fenómeno es atribuible a vientos norte y sur, perpendiculares a la dirección de la duna lineal. Por lo tanto, se trata de un sistema reverso. En el momento de la observación de terreno, se vió rasgos de precipitación en su microvertiente oriental, indicando que estas estructuras corresponden a vientos altamente variables. Hacia el W, el sistema de micro-ondulación da paso a una sucesión de estructuras transverso-transgresivas, a la manera de un cinturón superpuesto, siendo éste el sistema más común en la duna lineal. Se acusa una mayor influencia del viento $\mathrm{W}$

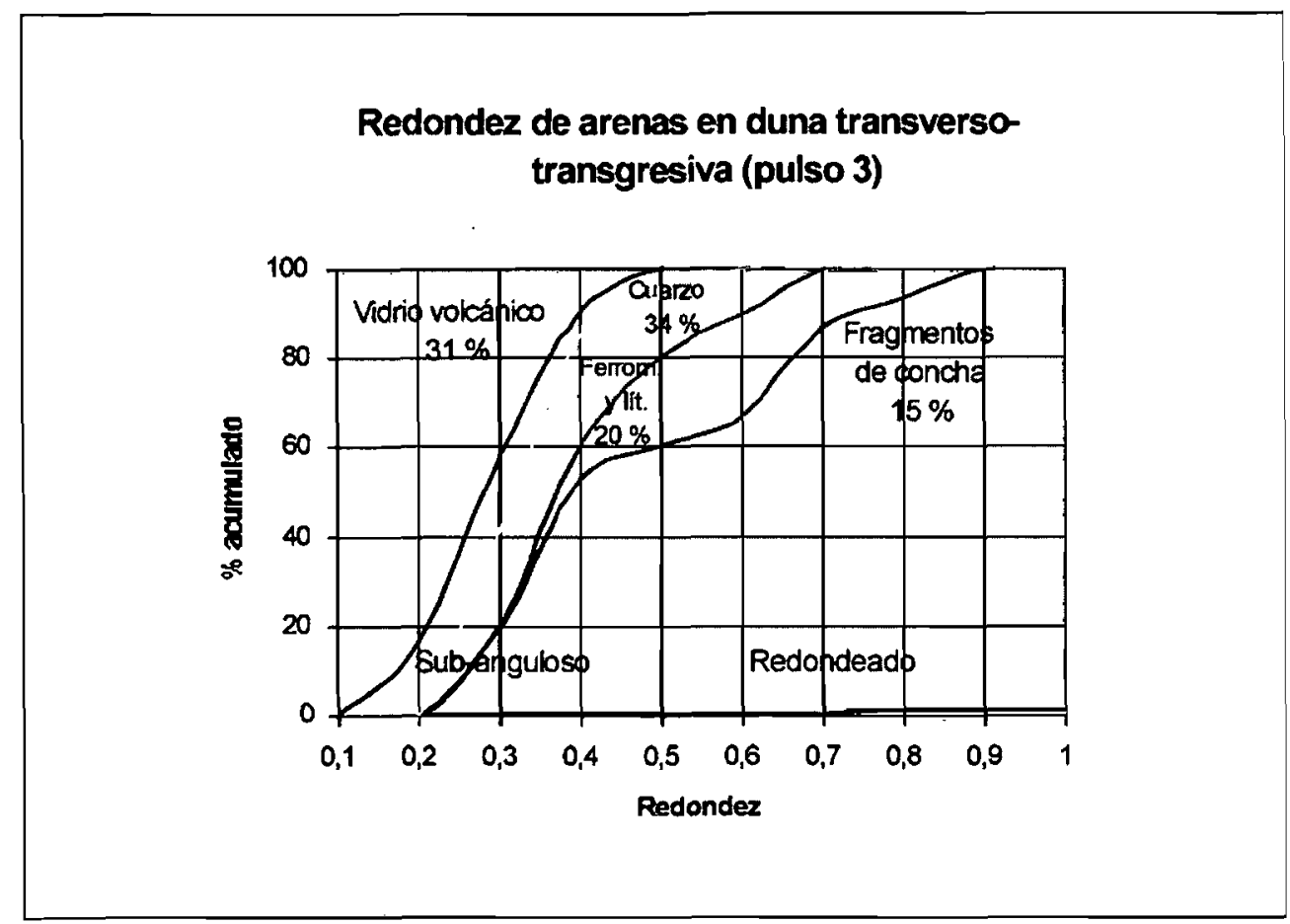

Fig. 14. Mar de Dunas Bajo a Medio Norte: penúltimo pulso formador de dunas estabilizadas.

Fig. 14. Northern Middle Sea of Sand: penultimate pulse, formative of stabilized dunes. 


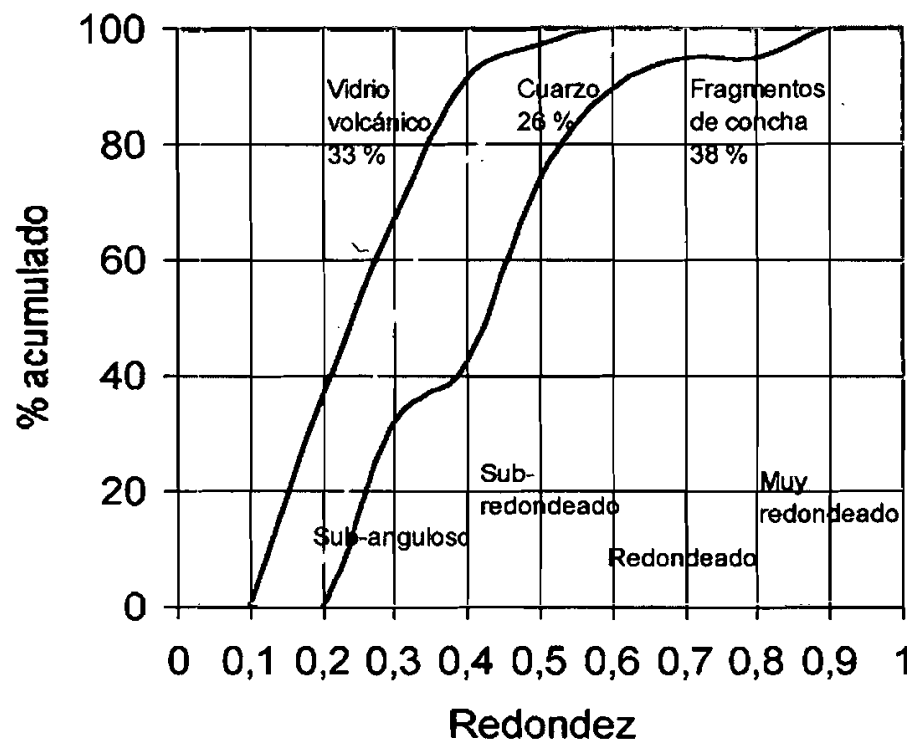

Fig. 15. Junto a Playa Ramadas: dunas estabilizadas de supralitoral. Fig, 15. Close to Ramadas Beach: backshore stabilized dunes.

en su construcción. Esto sugiere que el grado de variabilidad del viento cambia localmente, siendo mayor donde se advierte presencia de micro-ondulaciones tipo La Ballena, debido a influencias topográficas localizadas. Pero el continuo afloramiento de vegetación esteparia en la parte media y baja de las vertientes del sistema lineal, indica que su masa esencial pertenece a pulsos anteriores al 5 y que este último afecta sólo a la parte superior del cordón. Estos rasgos de actividad presente no se manifiestan hacia el cono de expansión mediante el sistema de inyección del pulso 3 , razón por la que la actividad presente de la duna lineal del sistema La Ballena no lo afecta.

Las otras manifestaciones del pulso 5 están en la parte alta del cono de expansión (Figs. 16 y 17). Ellas indican un proceso importante de barjanización. Debido a la macicez del sistema, los elementos parabólicos están siempre presentes, conformando sistemas transverso-transgresivos. Crestas reversas y dunas anidadas aparecen donde la variabilidad del viento aumenta en las parte más altas.

\section{Erg Sur}

Mar de Dunas Bajo y Medio Sur (Figs. 2 y 19 a 21)

En este mar de arenas se observa cuatro pulsos formativos.

Pulso 1: Esta fase está representada esencialmente en el cono de expansión aklé (Mar de Dunas Medio), con longitudes de onda menores que las de los otros conos $(\sim 120-125$ $\mathrm{m})$, correspondientes a aklé anidado poligonal, aklé degradado de crestas suaves y aklé típico con parab́licas imbricadas (Fig. 20). En general, se trata de formas suaves, inactivas y vegetacionadas. Hacia las partes altas, las parabólicas imbricadas presentan reactivaciones con vertientes de precipitacion. 

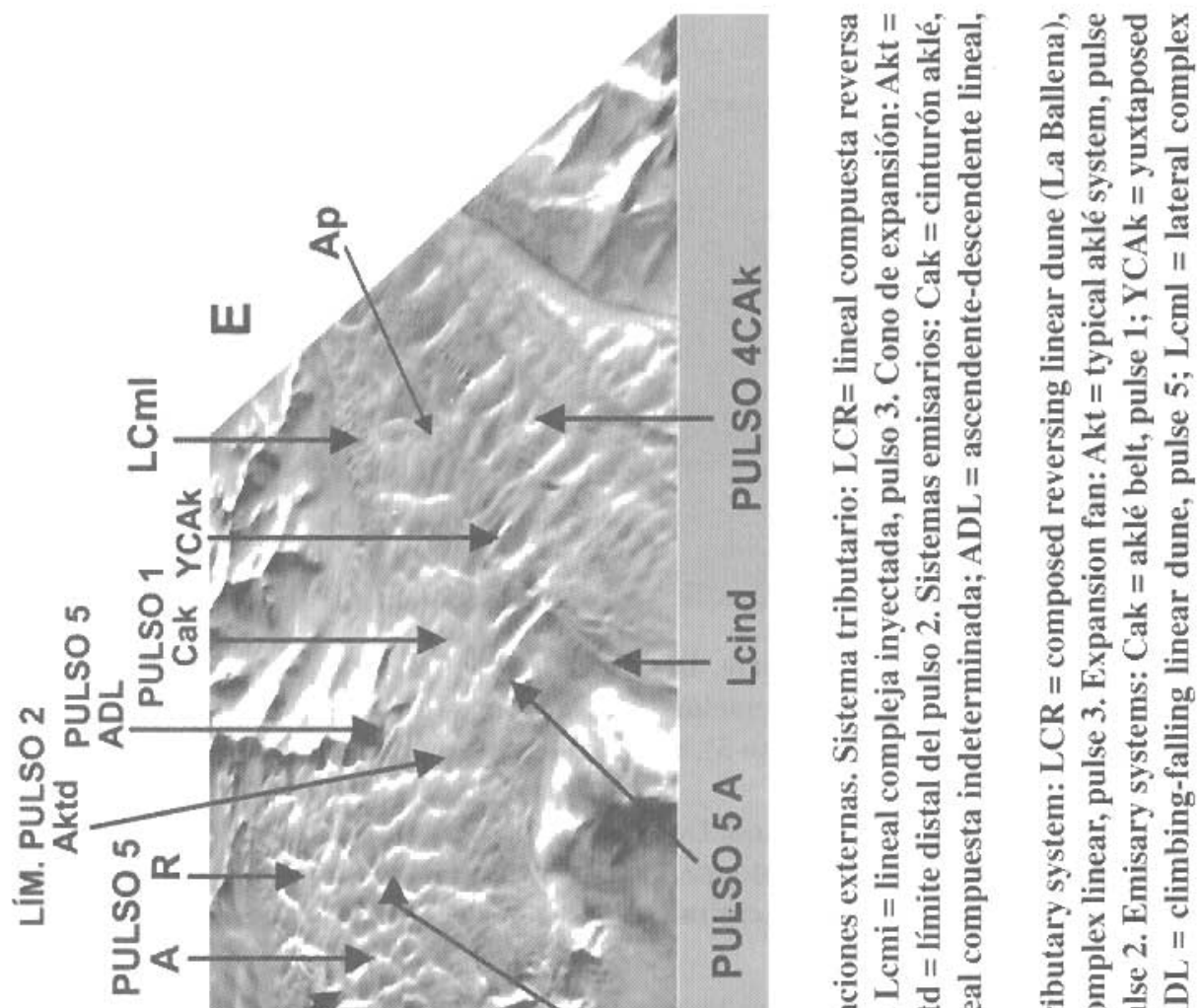

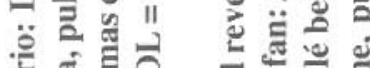

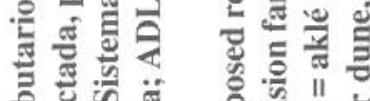

ह

E.

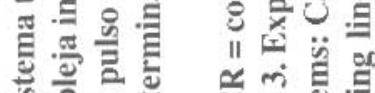

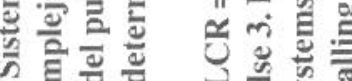

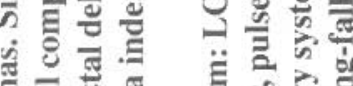

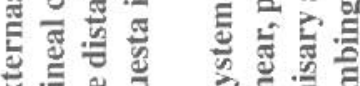

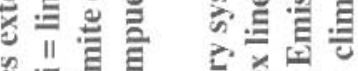

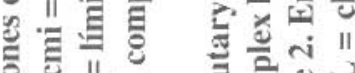

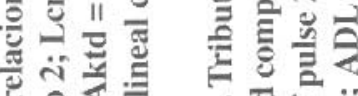

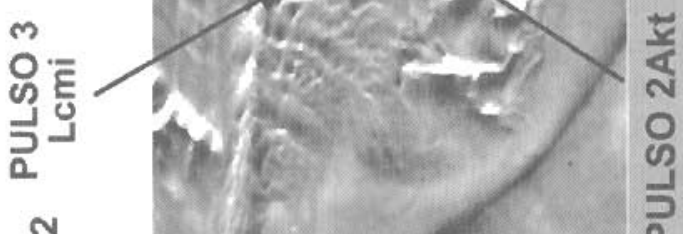

> $\ddot{2}$ iा

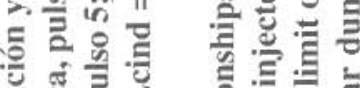

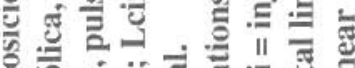

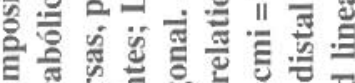

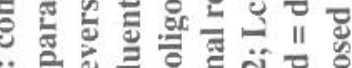

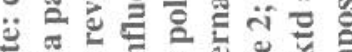

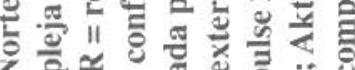
틍

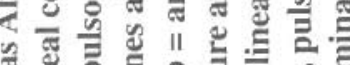

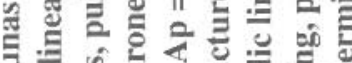
크ำ

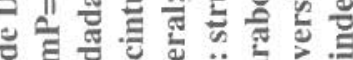

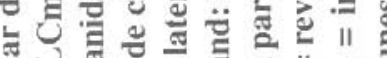
要 ๊ ए

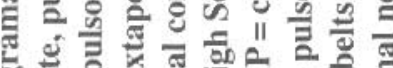

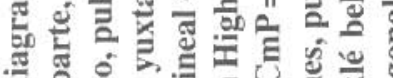

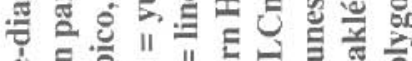

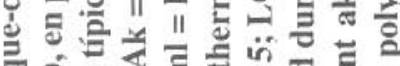

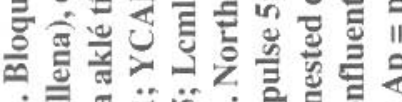
生

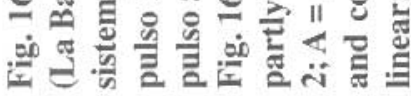




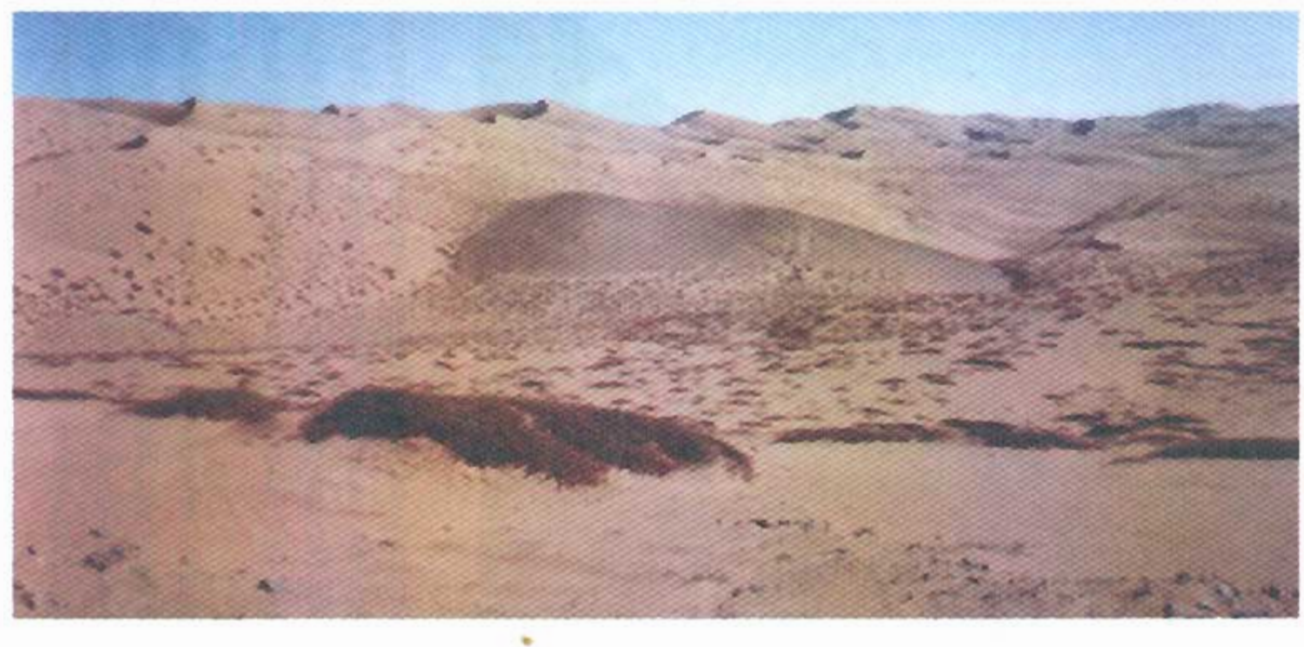

Fig. 17. Mar de Dunas Alto Norte. Detalle del aklé típico de parabólicas inactivas en primer plano (pulso 2), con vegetación esteparia baja. Al fondo, aklé activo barjánico y parabólico en la parte alta (pulso 5), con vertientes de precipitación y algunas reversas (Fig. 16).

Fig. 17. Northern High Sea of Sand. Detail of the typical aklé of inactive parabolic dunes, pulse 2 (foreground), with low steppe. Background: active barchanic-parabolic aklé in the high part (pulse 5), with precipitation and some reversing slopes (Fig. 16).

Pulso 2: Está compuesto por dunas lineales simples longitudinales del sistema tributario, inyectadas en el aklé del pulso 1 del cono de expansión, sobreyaciéndolo (Fig. 21). Su patrón en «corduroy» o «côtelé» es homólogo del pulso 2 del Mar de Dunas Bajo a Medio Norte.

Pulso 3: Está representado por el cinturón transgresivo-aklé, asociado al sistema tributario, en el que los elementos transgresivos tienen modelado suave, son inactivos y colonizados por estepa baja. Recubre parcialmente a las lineales longitudinales del pulso 2 y al aklé del cono de expansión en su parte proximal (Fig. 21).

Pulso 5 (Fig. 19): En el aklé del cono de expansión, recubre a la proyección distal de las longitudinales del pulso 2, con transgresivas de operación presente, generadas a partir de las dunas del pulso 1. En la parte más alta del cono de expansión, el sistema se hace abiertamante transverso-transgresivo, mostrando elementos reversos y dunas anidadas. En el portezuelo que lo comunica a sotavento con el Mar de Dunas Alto Sur, el sistema emisario consiste principalmente en una duna lineal compuesta (Fig. 2), reversa a indeterminada con algunos elementos parabólicos. Hacia la cresta, la duna es activa, pero su cuerpo principal corresponde mayoritariamente al pulso 3 . Se trata de un cinturón de derivación (bypass).

Anomalía del cono de expansión (Fig. 19): En la parte sur este mar se encuentra disectado por una red de canales que se abren hacia el $\mathrm{N}$ en forma de abanico, presentando conjuntamente una serie de cordones paralelos a estos canales. Se trata de un sistema con formas suaves, estable y sin señales claras de reactivación dunar. Parece ser resultado de drenaje fluvial, correlativo a una cuenca receptora inmediata.

Mar de Dunas Alto Sur (Figs. 2, 22 y 26)

Sus enlaces con barlovento (sistema tributario) son la duna lineal compuesta reversa de derivación (bypass) al Norte y el cinturón ascendente-descendente al Sur (Fig. 22). La secuencia formativa de este sistema es como sigue: 
Pulso 1: Sistema aklé típico (Fig. 22), que constituye el cuerpo principal del cono de expansión. La orientación de las crestas dunares indica que su material procede tanto del sistema de derivación como del cinturón ascendente-descendente. Las formas parabólicas elementales son fundamentalmente vegetacionadas e inactivas, en las que las vertientes de precipitación son escasas o inexistentes. El carácter imbricado de las unidades parabólicas, con cordones rezagados cortos y notorio desarrollo transversal de las crestas, refleja compresión importante del conjunto, por influencia topográfica de la cuenca. En la parte alta del cono de expansión, las dunas de este pulso están parcialmente recubiertas por ejemplares del pulso 5 (Fig. 23).

Pulso 2: Se trata de una fase transgresiva con respecto al pulso 1. Revela las mismas direcciones de procedencia que para éste, al cual sobreyace, ocupando sus depresiones. Por lo tanto, la configuración del conjunto es alargada y no compacta como la del pulso 1 . Las unidades parabólicas son también imbricadas, con patrón aklé, pero las crestas tienen escaso desarrollo transversal. Se trata de un aklé inyectado en el cono de expansión y se puede incluir en el sistema tributario (Fig. 22); es preferentemente inactivo, con estepa y escasez de vertientes de precipitación.

Pulso 3: Está directamente asociado con la duna lineal de derivación y con el cinturón ascendente-descendente del sistema tributario, sin ser parte substancial de ellos, sino del cono de expansión, conformando un rasgo especializado del aklé (Figs. 22 y 24). La sección relacionada con la duna lineal de derivación está compuesta de formas lineales parecidas a aquella. Se trata de desarrollos lineales rugosos, debidos a una corta longitud de onda entre crestas ( $50-80 \mathrm{~m})$. Éstas

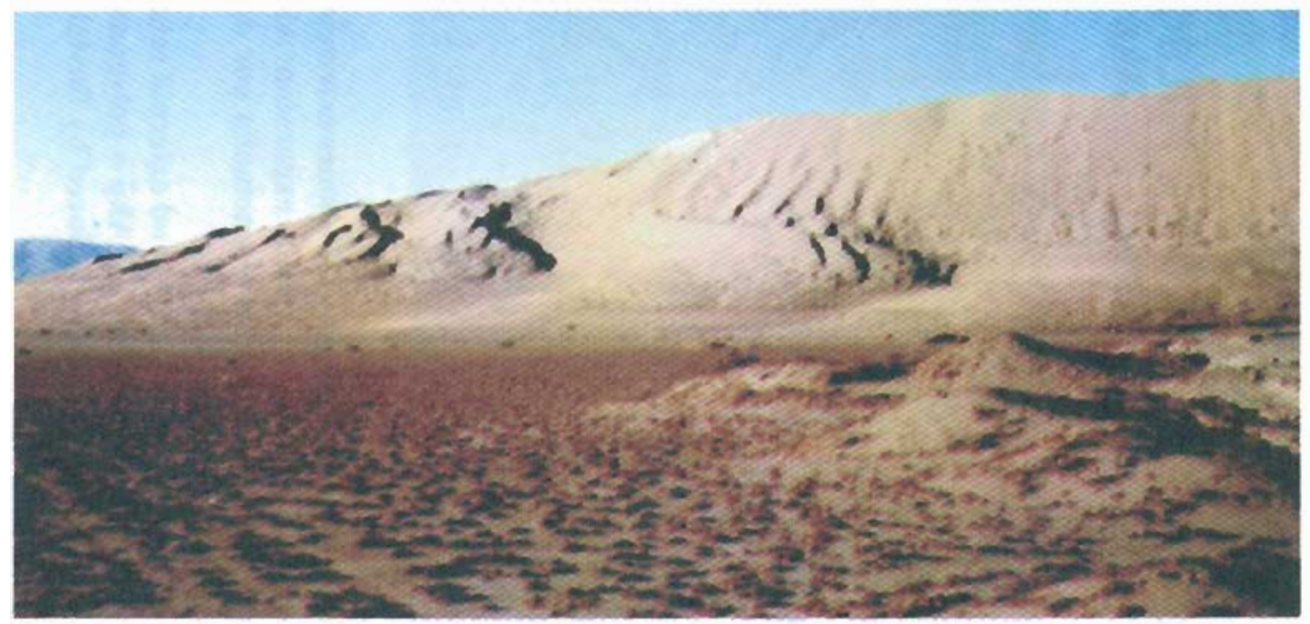

Fig. 18. Mar de Dunas Alto Norte. Sistema tributario. Duna lineal compuesta reversa (La Ballena); segmento visto desde el S. Dos partes: hacia el E (derecha) ondulación de onda corta en vertiente (observar los elementos barjánicos y parabólicos alargados en la dirección de la vertiente, como «tubos de órgano»); hacia el W (izquierda) cinturón transverso transgresivo. El límite de la vegetación de la parte baja indica actividad sólo en la parte alta.

Fig. 18. Northern High Sea of Sand. Tributary system. Composed-reversing linear dune (La Ballena); sight of segment from the $\mathrm{S}$. Two parts: eastward (right) short wave ondulation in the slope (observe the elongated barchanic and parabolic elements in the direction of the slope, seeming «pipes of organ»); westward (left), transverse-transgressive belt. The limit of the vegetation of the low part indicates activity only in the hight part. 

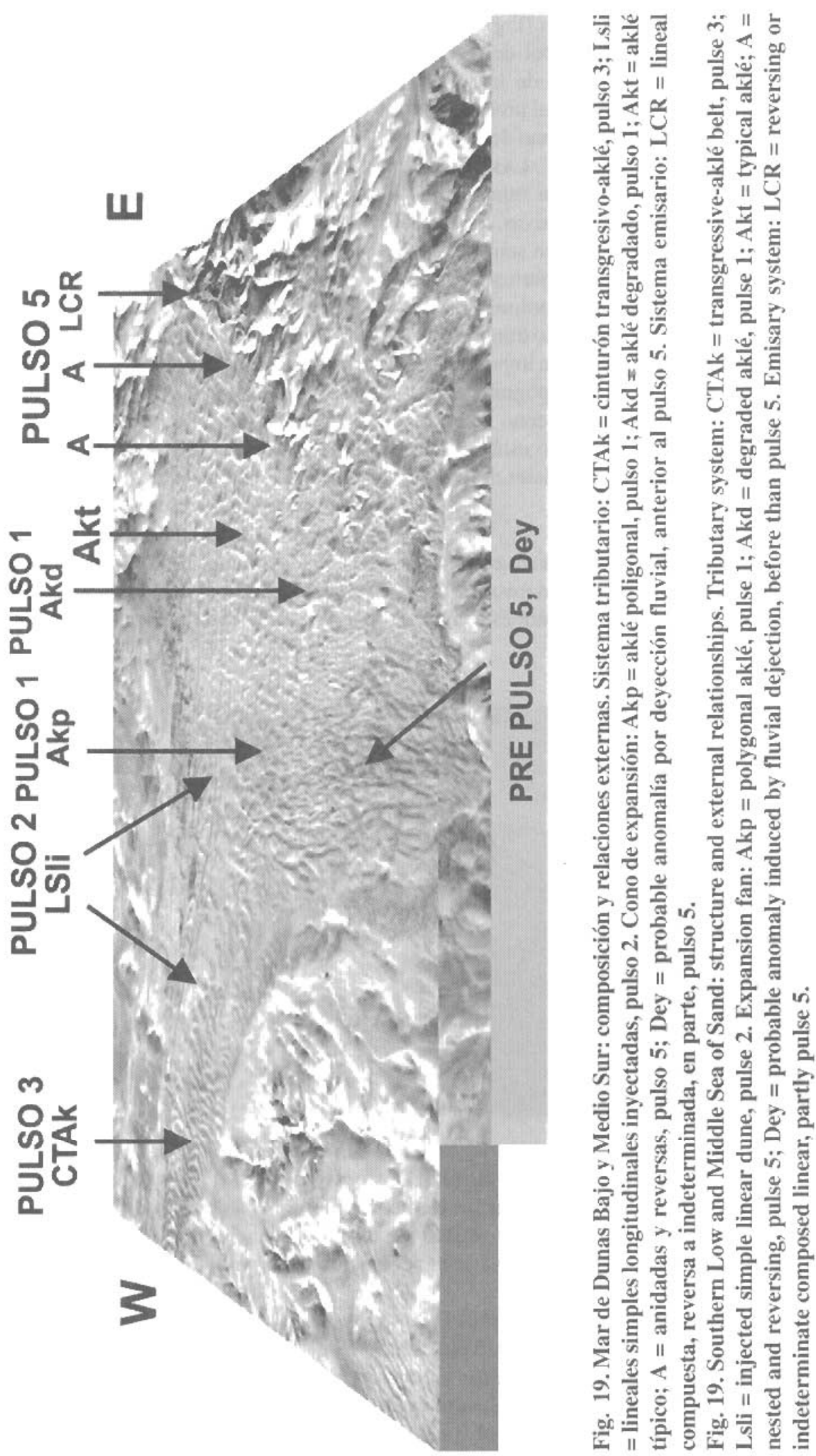
corresponden a unidades parabólicas estrechamente cabalgadas e imbricadas, en un estilo parecido a "gusano segmentado» (Fig. 24), lo que indica acreción desde sotavento a barlovento e importante compresión de masa; aparecen como formas lineales compuestas yuxtapuestas. Los segmentos constituyen un conjunto rítmico; son formas suaves, estables y con estepa baja. El pulso parece formar parte importante del cuerpo de las dunas lineales de sistema tributario, que presentan elementos vegetacionados en la parte baja y activaciones del pulso 5 en las vertientes superiores.

Pulso 5: El pulso presente se manifiesta principalmente en tres casos (Fig. 22 y 26): 1) En el sistema tributario norte, que incluye la duna lineal compuesta y reversa de derivación (bypass) y la duna lineal compuesta y reversa inyectada (o duna lineal de vertiente). En la primera, opera en la parte superior del cordón, conformando una cresta reversa simple. En la segunda, lo hace principalmente en la vertiente norte (Fig. 25), generando una estructura de formas como la de La Ba-
Ilena (en el Sistema Norte, Fig. 18), consistente en ondulaciones de corta longitud de onda (30-34 m), debidas a una sucesión de formas barjánicas, muy coalescentes y alargadas y algunas parabólicas, que se extienden en la dirección de toda la vertiente. En la vertiente sur, las formas son parabólicas, más anchas y cortas; corresponden a una vertiente más baja por estar apoyada en terreno preexistente más alto. La duna es francamente reversa, con probable operación predominante del viento norte e importante actividad del viento suroeste; es asimétrica en perfil N-S. Esta característica se exagera al inyectarse lateralmente el sistema en el cono de expansión, hasta constituirse en dunas transgresivas impulsadas por viento norte (Fig. 24). 2) En el cinturón de ascenso y descenso, compuesto exclusivamente de dunas activas. Del recuadro de la Fig. 26, se deduce que sus arenas han sido suministradas por un sistema de dunas parabólicas y upsiloidales antiguas ubicado en la localidad de Margarita en el fondo del valle del río Copiapó, debido a un proceso de reactivación. Desde aquí, la secuencia de barlovento a sotavento muestra

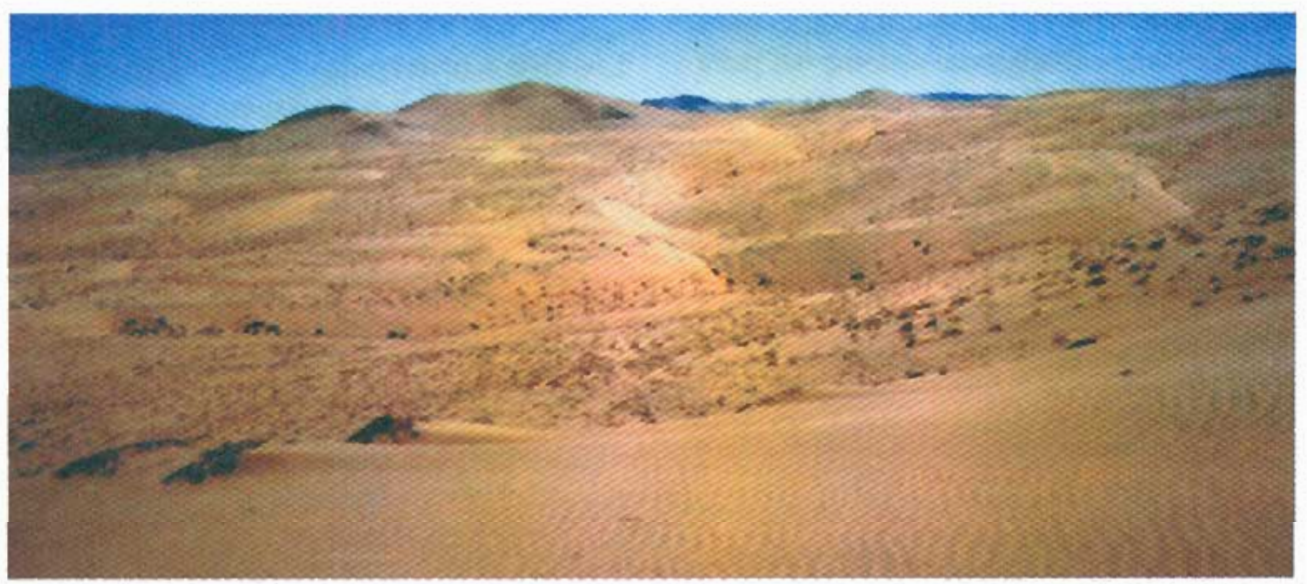

Fig. 20. Mar de Dunas Medio Sur. Cono de expansión. Patrón aklé típico (Fig. 19), con dunas parabólicas imbricadas, relativamente suaves, vegetacionadas, en gran parte inactivas y algunas activas con vertiente de precipitación. Un elemento barjánico al centro y los ripples del primer plano indican reactivaciones.

Fig. 20. Southern Middle Sea of Sand. Expansion fan. Typical aklé pattern (Fig. 19); parabolic imbricated, relatively smooth, vegetated and inactive dunes; some of them are active with precipitation slopes. $\mathrm{A}$ barchanic element at center and ripples at foreground indicate reactivation. 
un comportamiento sistemático del cinturón, según se trate de ascenso o descenso, zonificádose como sigue: a) En la vertiente SW de Sierra Piedra Colgada, el ascenso se expresa preferentemente en dunas upsiloidades y longitudinales a barlovento y en parabólicas de brazos cortos y algunas longitudinales a sotavento, cerca de la divisoria. b) A sotavento de la divisoria, la zona corresponde a dunas longitudinales, tanto en descenso como en ascenso, hasta la divisoria siguiente. c) A sotavento de ésta, el derrame de masa por descenso comienza con longitudinales, las que dan paso a cinturones de barjanes (Fig. 27) que se proyectan por la vertiente de ascenso. d) Hacia la divisoria de la zona de ascenso, el cinturón alcanza a un sistema comprimido aklé del pulso 3, a través de un patrón longitudinal. e) El sistema delimita la parte sur del cono de expansión con un conjunto dunar lineal reverso (Fig. 28). f) A sotavento de la divisoria de Cerro Chamonate (Fig. 2) la masa arenosa se presenta como derrame de sotavento, correspondiente a zona de descenso, con dunas longitudinales a barlovento y sistema aklé a sotavento, ingresando masa hacia el valle de Minera Atacama, donde se comprime. 3) En las partes altas distales del sistema del pulso 1 hay reactivación de sus arenas, representa- da por dunas transgresivas con altas vertientes de precipitación, correspondiendo al viento dominante SW indicado por la flecha. Sin embargo, las incidencias de viento sur parecen importantes sobre $1000 \mathrm{~m}$ de altitud, cerca de la divisoria de $\mathrm{C}^{\circ}$ Chamonate, a juzgar por la presencia de grandes barjanes superpuestos, cuyos cuernos y vertientes de precipitación apuntan al N. Características de este emplazamiento son las dunas reversas anidadas en forma de embudo, que indican vientos variables (Fig. 29).

\section{DISCUSIÓN}

\section{Morfología y emplazamiento de los pulsos}

Los sistemas del pulso 1 conforman estructuras aklé típicas emplazadas en los conos de expansión de las cuencas amplias. Esto significa un proceso integral de expansión lateral del flujo arenoso, pero con compresión longitudinal de estructuras parabólicas, debido a sobrecarga de masa arenosa. La organización de aklé en formas horizontalmente cónicas no estaba hasta ahora descrita en la literatura

Los sistemas del pulso 2 son de tres categorías: dunas lineales longitudinales de estruc-

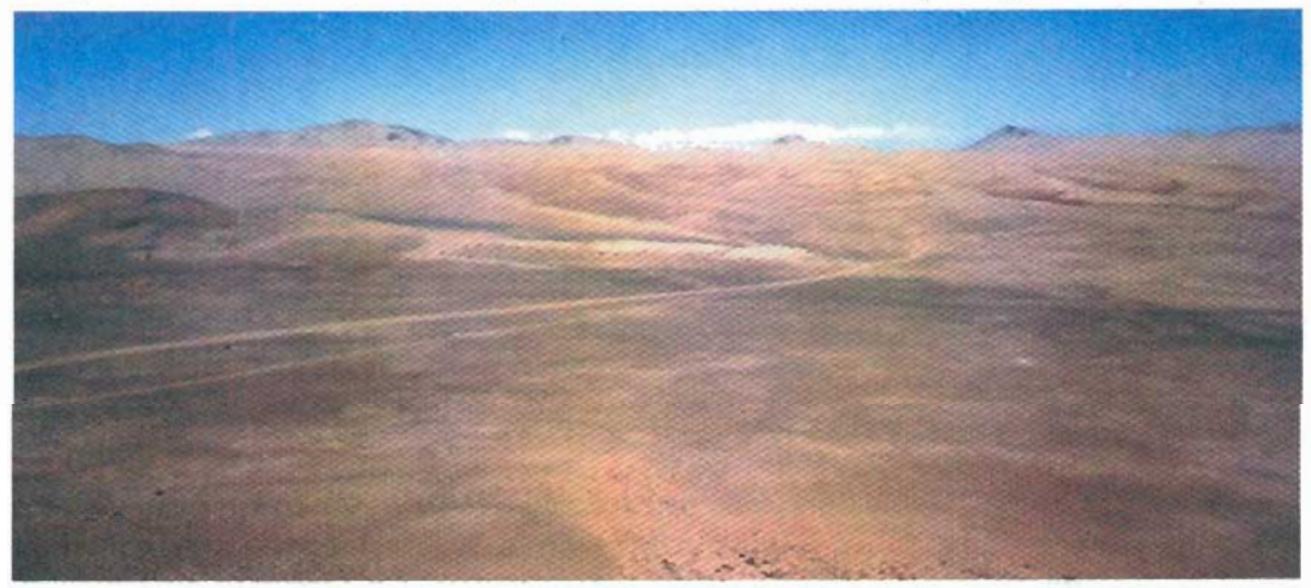

Fig. 21. Mar de Dunas Bajo Sur. Relaciones aloestigráficas entre pulsos 1, 2 y 3. Al fondo e izquierda, dunas lineales longitudinales recubriendo al aklé del pulso 1 . Al frente y derecha, cinturón trnasgresivo-aklé recubriendo a dunas lineales.

Fig. 21. Southern Low Sea of Sand. Allostratigraphic relationships between pulses 1, 2 and 3. Background and left: longitudinal linear dunes overlaying the aklé of pulso 1 . At front and right: transgressive-aklé belt overlaying linear dunes. 


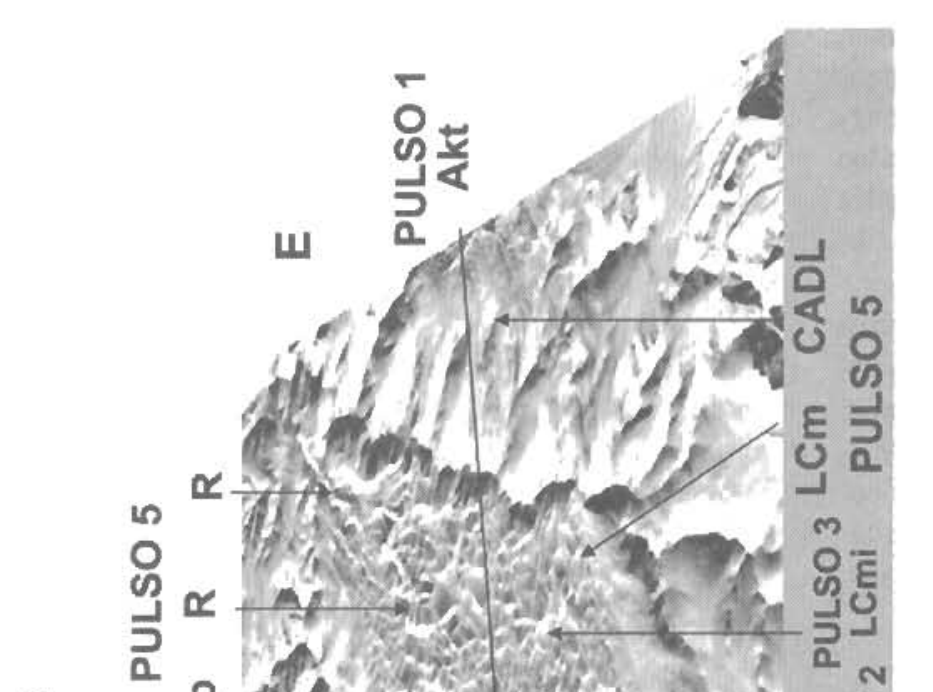

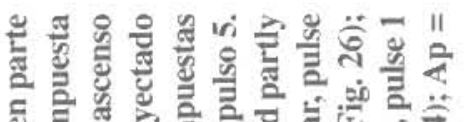

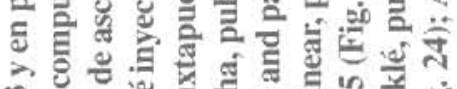

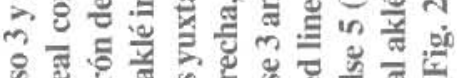

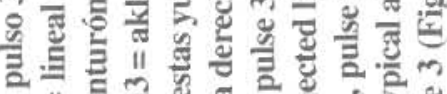

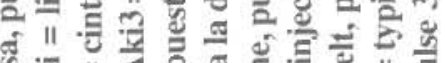

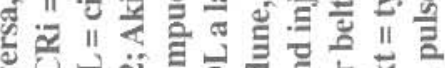

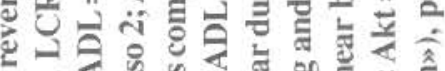

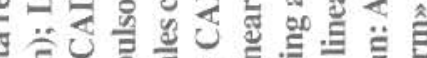
乌ั

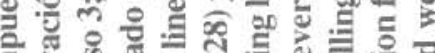
ह

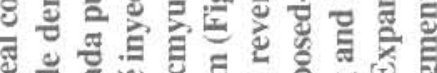

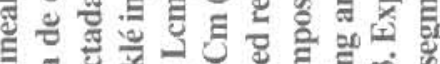

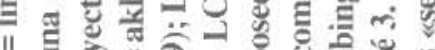

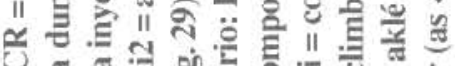

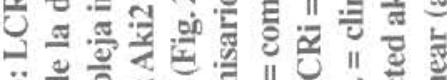

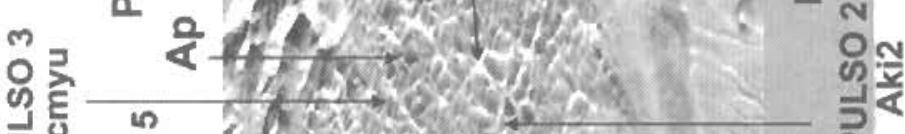

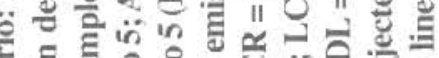

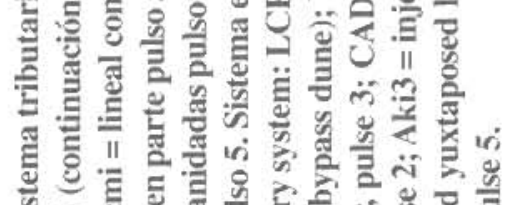

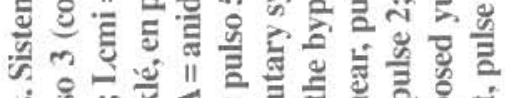

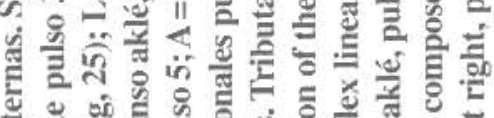

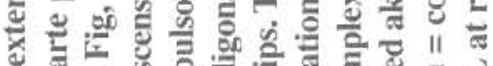
ڤัँ

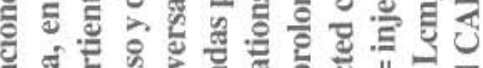

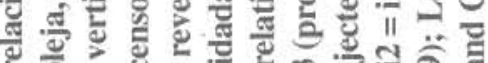

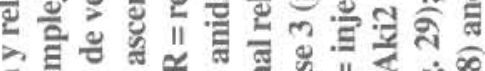

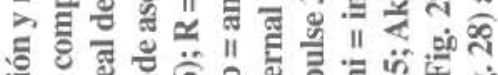

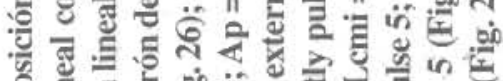

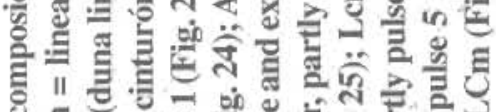

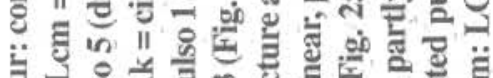

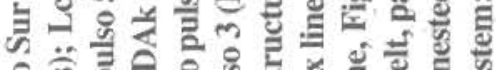

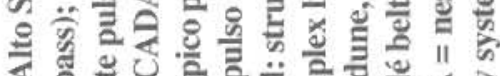

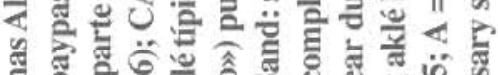

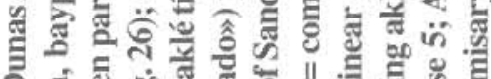

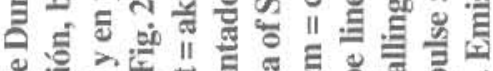
월

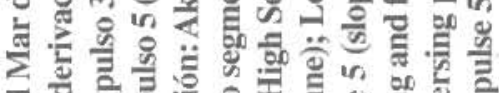
ธัฐ

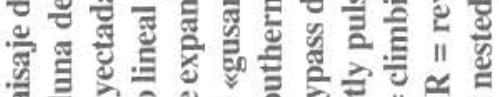

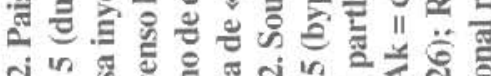
ส่ '?

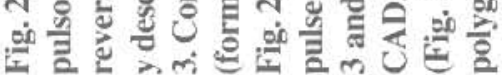


tura corduroy en mar de dunas bajo, donde las dunas lineales complejas están ausentes; aklé inyectado en depresiones alargadas, como sistema tributario de cono de expansión en mar de dunas alto; y en cono de expansión en mar de dunas alto. A este pulso también parecen pertenecer las upsiloidades asociadas a los yardangs.

Los grupos del pulso 3 conforman cinturones transverso transgresivos en sistemas tributarios de los mares bajos y medios y lineales complejas o compuestas inyectadas, relacionadas con el sistema tributario de los conos de expansión de los mares de arena altos. También parecen encontrarse en los surcos yardángicos, con estructura aklé.

Al exponer los resultados, se vió que el pulso 4 sólo está presente en la parte baja del erg norte, con estructura principal corduroy, asociada genéticamente con upsiloidales y parabólicas, constituyendo la parte más proximal de los dos ergs. Este tipo de patrón ha sido identificado en el mar de arenas de Wahiba (Omán), donde se ha constatado el origen marino del material (GOUDIE $e t$ al.
1987; PEASE et al. 1999). Similarmente, en el caso de Atacama sólo existe en los sectores más expuestos a la influencia costera directa.

El pulso 5 o presente se encuentra en sistemas tributarios, conos de expansión y sistemas emisarios. En sistemas tributarios de mares de arena altos aparece en los sectores activos de dunas lineales compuestas, conformando elementos reversos, siendo importante en las dunas de derivación (bypass); es dominante, y a veces exclusivo, en cinturones ascendente-descendentes, expresándose como lineales simples, parabólicas y barjánicas. En conos de expansión, aparece en las partes altas, comunmente distales, en formas de dunas reversas, anidadas, anidadas poligonales, parabólicas en aklé (con algunas barjánicas) y transgresivas. En sistemas emisarios, se halla en forma de lineal compleja y cinturón ascendente-descendente, lineal ascendente-descendente y lineal compuesta, reversa a indeterminada. Este pulso está también importantemente asociado a los yardangs, sobrepuesto a sus dorsos como duna lineal reversa.

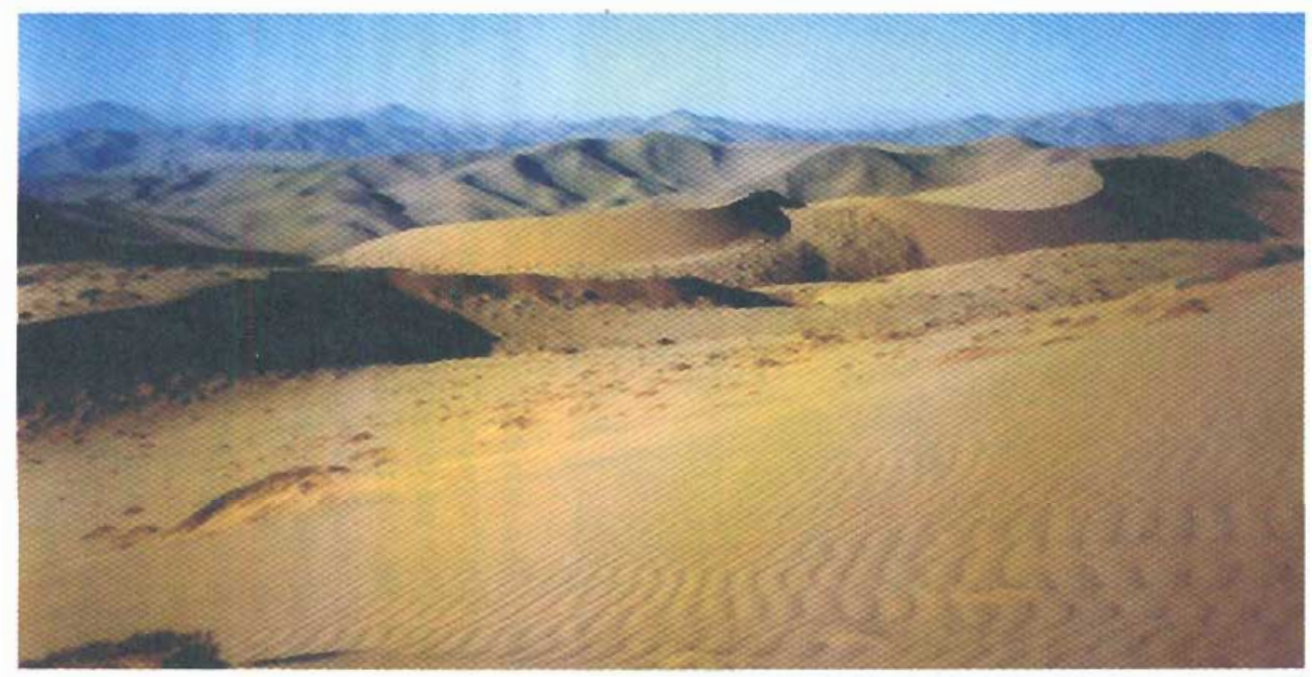

Fig. 23. Mar de Dunas Alto Sur. Cono de expansión. Sistema aklé, pulso 1, estable, de formas suaves y vegetacionado, recubierto parcialmente por parabólicas típicas del pulso 5. En primer plano, ripples de una de estas últimas.

Fig. 23. Southern High Sea of Sand. Expansion fan. Aklé system, pulse 1, inactive, vegetated and smooth; overlayed partly by typical parabolic dunes of pulse 5 . Foreground, ripples of pulse 5 . 


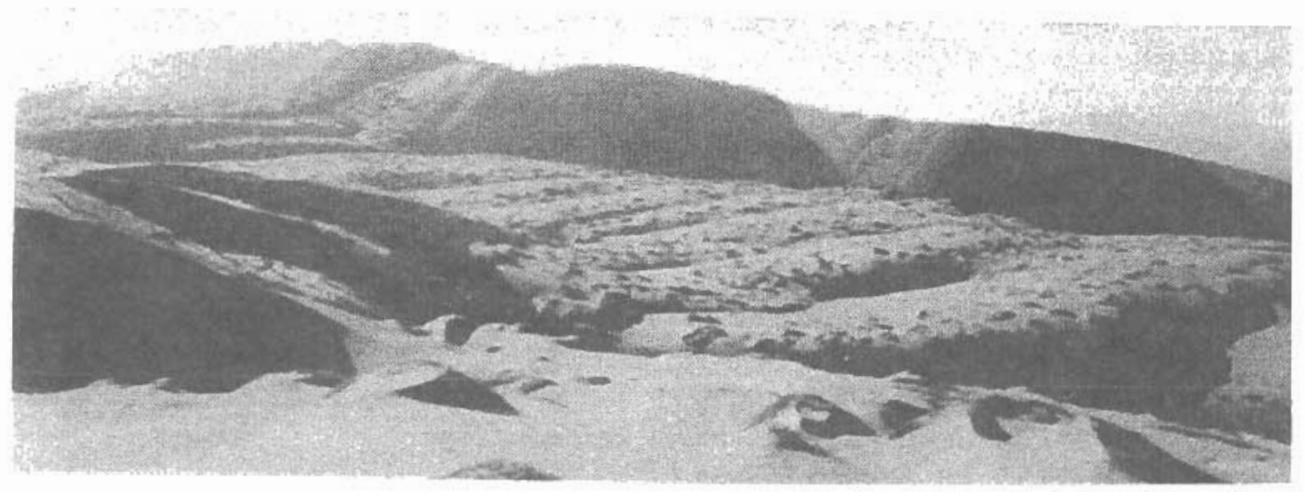

Fig. 24. Mar de Dunas Alto Sur. Cono de expansión. En primer plano, estructuras anidadas, pulso 5. En segundo plano, lineal compuesta, estructurada como «gusano segmentado", pulso 3 (Figs. 22 y 26). En tercer plano, duna transgresiva y reversa, pulso 5 , proyección distal de la duna lineal compuesta reversa inyectada (Figs. 22 y 25 ).

Fig. 24. Southern High Sea of Sand. Expansion fan. Foreground, nested structures, pulse 5. Middle distance, composed linear, structured as «segmented worm», pulse 3 (Fig. 22 and 26). Foreground, transgressive and reversing dune, pulse 5 , distal proyection of the composed, reversing and injected dune (Figs. 22 and 25 ).

Grado de asociación del pulso 5 (presente) con otros pulsos

El pulso 5 se manifiesta asociado a otros pulsos, en grados que varían entre dos extremos: a) En cinturones ascendente-descendentes, donde tiende a presentarse como único. En este caso, parece importante el efecto de la migración de barjanes y de las interacciónes de continua hasta el proceso de formación de transgresivas, con mecanismos como los observados por JIMENEZ et al. (1999) en el NE de Brasil o GAY (1999) en el S de Perú. b) Está ausente en el pulso 4, sin relación con dunas activas. Entre ambos extremos, los grados de asociación son variados, pero la presencia del pulso presente es decisiva en los cinturones de derivación (bypass) y en las zonas más elevadas de los conos de expansión. En el primer caso, los cuerpos fundamentales de las dunas lineales corresponden a los pulsos 2 a 3. En el segundo, la masa fundamental sobre la cual está organizado el pulso 5 es la del aklé de los pulsos I a 2. En ambos casos se aprecia relaciones genéticas entre sistemas de barjanoides. megabarjanoides y elementos longitudinales, de modo comparable a las experiencias recogidas en el Desierto de Thar (KAR 1990).
Mayor precisión podria lograrse si se estudiara rasgos de modificaciones postdeposicionales en dunas lineales, aplicando termoluminiscencia y alteración de las arenas (GOUDIE et al. 1993). El efecto geomorfológico de esta asociación de pulsos es parecido al encontrado en otros casos. Así, observaciones en Médoc (Francia) indican que las dunas parabólicas ascendentes (coalescentes compuestas) son de baja altura en la generación vieja, mientras las barjánicas son altas (TASTET \& PONTEE 1998), lo que es observable en los ergs de Atacama. Ellos también muestran influencia de los vientos variables en las partes más expuestas. La tendencia morfogenética correspondiente puede comprenderse de las experiencias de VAN BOXEL et al. (1999) y VAN DIJK et al. (1999), modelando el transporte de sedimentos a través de dunas transversales y el desarrollo de su perfil. Se observa de esto que el viento unidireccional produce un crecimiento vertical despreciable, con migración constante de las crestas. Inversamente, el viento de dirección cambiante forma dunas altas (Figs 24, 28 y 29). Este proceso debe estar relacionado con los flujos secundarios, el efecto de "suspended fallout» (a contrapendiente) y los distintos rangos del 
ángulo de incidencia en dunas reversas (WALKER 1999). Observaciones de McKENNA NEUMAN et al. (2000) sugieren que los vientos moderados conducen a erosión cerca de la duna y aplanamiento de la forma, en tanto que los vientos fuertes incrementan la altura y el peralte, lo que tiene profundas implicaciones morfogenéticas. Ellas han sido encontradas observando la interacción entre vientos dominantes, relieve y condiciones de vientos de tormenta (BIGARELLA 2000). La inclinación de la vertiente de barlovento fue modelada por la simulación del efecto de «speedup» (aceleración) del viento en la formación de campos de dunas transversas (MOMIJI et al. 2000 ), de lo que se comprende que dunas activas puedan existir a expensas de las arenas de dunas más antiguas, donde la celeridad del viento aumenta. Para la construcción de modelos sobre estos mecanismos, las ob- servaciones recogidas por WILSON (1971) señalan que los ergs están rara vez en equilibrio con su sistema de flujo de arena presente. No está claro el proceso de activación de arena a partir de dunas vegetacionadas y estables. Sólo se conoce la observación de patrones de transporte en dunas anteriores vegetacionadas (ARENS 1996).

\section{Interferencias topográficas en el desarro-} llo de los ergs

El grado de interferencia topográfica se refleja en las categorías dunares, su emplazamiento en función de la distribución de las cuencas y en su grado de actividad. Los mares de arena sin interferencia topográfica importante están asociados a fondos de valle abiertos a la costa; contienen cinturones transverso-transgresivos y sistemas corduroy de lineales simples, las que son más típicas.

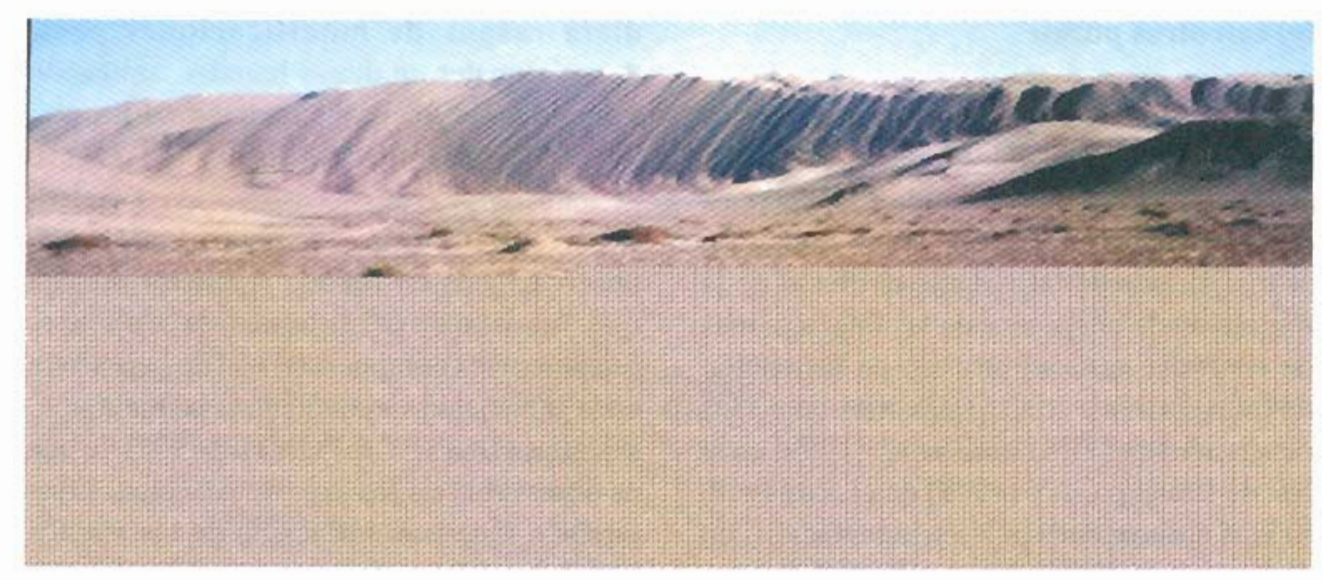

Fig. 25. Mar de Dunas Alto Sur. Duna lineal compuesta reversa inyectada en la parte norte del cono de expansión (Figs. 22 and 26), vista desde el Norte (llamada Duna Madre). La rugosidad de onda corta en la dirección de la vertiente corresponde a estrechas formas barjánicas coalescentes, activadas por viento NNE, más algunas upsiloidales, tomando la forma de «tubos de órgano» (pulso 5). El interior de la duna parece corresponder al pulso 3 , lo que se aprecia hacia sotavento y barlovento, sin estructuras de onda corta. En primer plano, terrenos de glacis con algunos afloramientos de reg.

Fig. 25. Southern High Sea of Sand. Composed, reversing and injected linear dune, in the northern part of the expansion fan (Figs. 22 and 26), sight from de $\mathrm{N}$ (named «Duna Madre»). The short wave roughness in the direction of the slope is composed to narrow coalescent barchans and some upsiloidal dunes, formed by NNW wind, appearing as «organ pipes» (pulse 5). The principal body of the dune is thought to be pulse 3 , because toward the lee and windward there are no short wave structures. Foreground: surface of glacis and reg. 


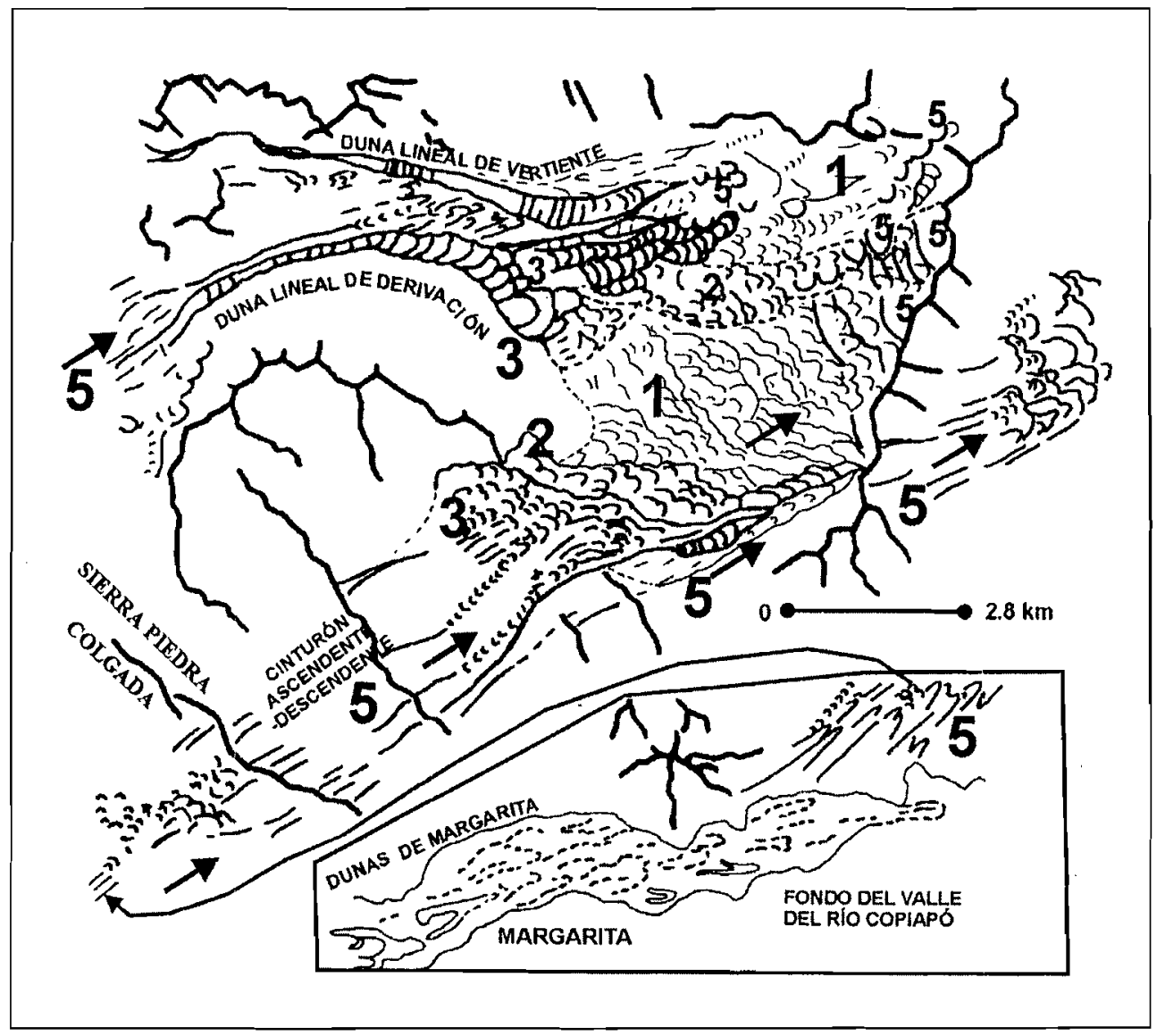

Fig. 26. Mar de Dunas Alto Sur. Croquis geomorfológico, referente a la Fig. 22. Estructura típica de un cono de expansión y formas asociadas. Los números indican los pulsos (ver Figs. 23 a 29). El recuadro señala la relación entre el cinturón ascendente-descendente y la zona de abastecimiento de arena.

Fig. 26. Southern High Sea of Sand. Geomorphological sketch, dealing with Fig. 22. Typical structure of an expansion fan and associated landforms. The numbres indicate the pulses (see Figs. 23 to 29). The inset shows the relationship between the climbing and falling belt and the sand supply zone.

Este hecho puede agregarse como argumento para interpretar a estas últimas como longitudinales (por alargamiento de parabólicas), si se tiene en cuenta el desarrollo de lineales en los mayores ergs de desierto del mundo (WASSON et al. 1988; WALKER 1986), donde las lineales simples parecen darse en los terrenos más planos con vientos menos variables. Esto resalta la importancia del estudio sobre variabilidad morfológica de dunas lineales. Usando la clasificación del patrón planimétrico de BULLARD et al. (1995) y sus aplicaciones con respecto a la red de drenaje (BULLARD \& NASH 1998), las dunas lineales simples de los pulsos 2 y 4 entran en la clase 2, encontrada en el Kalahari. Ésta consiste en dunas paralelas a subparalelas y continuas por varios $\mathrm{km}$, ausencia o rareza de elementos transversales y pocas uniones en $y$.

En cambio, las lineales de derivación (bypass) - inducidas topográficamente - se diferencian de las simples por ser únicas (sin cordones paralelos), por contener elementos transversales inherentes a ellas (compuestas o com- 
plejas) y por tener importantes partes activas. Esto es consistente con las observaciones de VERSTAPPEN (1972) en el Desierto de Thar sobre dos consecuencias de la obstrucción topográfica en el sistema dunar: desviación del viento y efecto de embudo. En los ergs de Atacama es claro que ellas causan el bypass y la mantención de la parte activa de la duna respectivamente. Mientras la derivación asocia a la forma con vientos variables relacionados con la complejidad topográfica, el efecto de embudo aumenta la velocidad del viento, manteniendo la actividad a lo largo del valle de derivación. De esta manera, la composición y complejidad morfológica de la duna están asociadas a las complicaciones inherentes al efecto de embudo.

En el caso de las cuencas amplias se aprecia dos fenómenos aparentemente antitéticos: la expansión de la masa arenosa y la compresión de compartimentos de la misma; pero la expansión en cono es lateral, una especie de deyección de arena; en cambio la compresión es longitudinal y proporcional al grado de obstrucción topográfica, a juzgar por la disminución de las longitudes de onda. La presencia de sistemas activos en las partes más altas de estos conos de expansión fue tratada al discutir la interación entre las dunas del pulso 5 y otros pulsos. Es necesario agregar aquí que las estructuras anidadas deben considerarse claves, puesto que reflejan la interacción entre el fenómeno de compresión y una definible variabilidad del viento. La nueva categoría observada, denominada aquí anidada poligonal, parece importante, puesto que debe expresar un fenómeno de economía de espacio. Puede tratarse de casos de extrema territorialidad, donde las estructuras aklé comprimidas interactúan con vientos variables.

Problemas genético-evolutivos; grado de simultaneidad de los pulsos a escala de $e r g$

Al menos desde el pulso 3 al 5 , las arenas presentan pocos rasgos de haber recibido un tratamiento eólico mecánicamente efectivo. El estado oxidado de los cuarzos es típico de

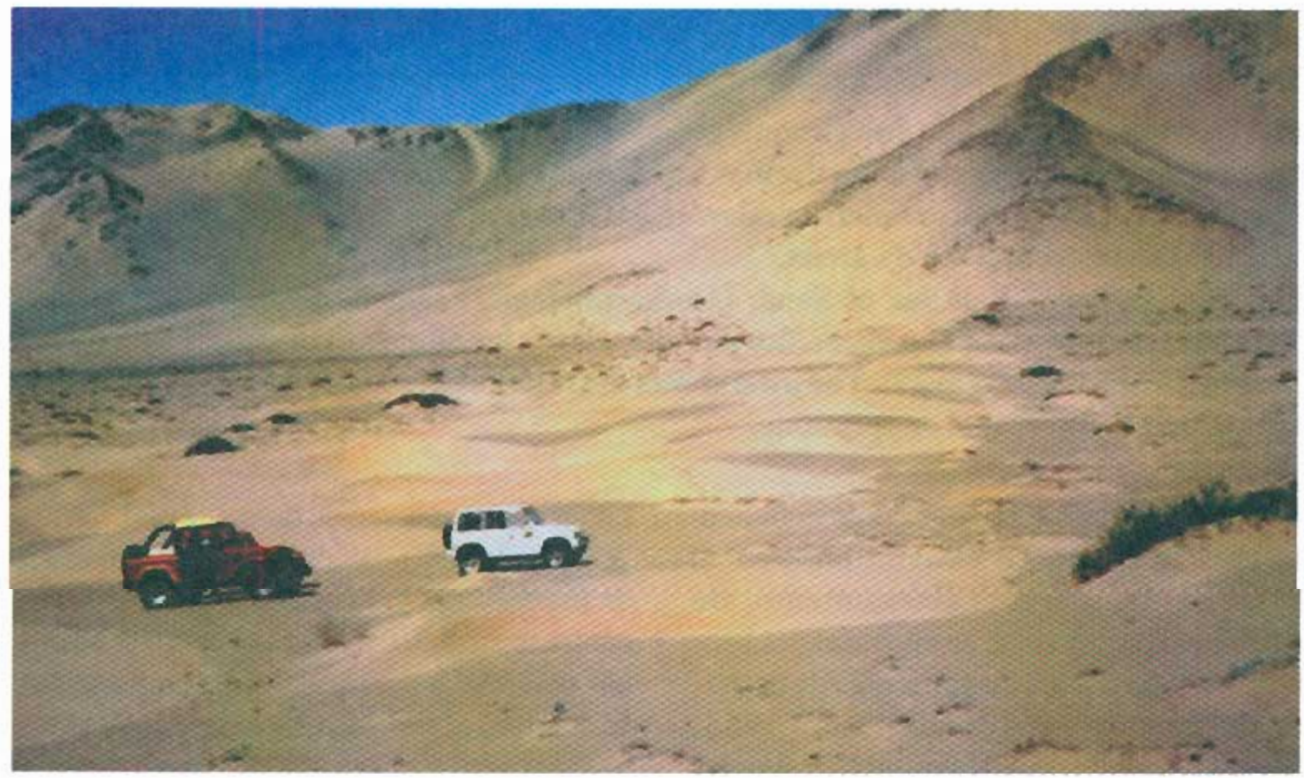

Fig. 27. Mar de Dunas Alto Sur. Sistema tributario sur. Cinturón ascendente-descendente (pulso 5, Figs. 22 and 26). Segmento de cinturón barjánico, a sotavento de Sierra Piedra Colgada (Derrame de sotavento).

Fig. 27. Southern High Sea of Sand. Southern tributary system. Climbing and falling belt (pulse 5, Figs. 22 and 26). Segment of barchanic belt, leeward of Sierra Piedra Colgada (Leeward sand overflow). 


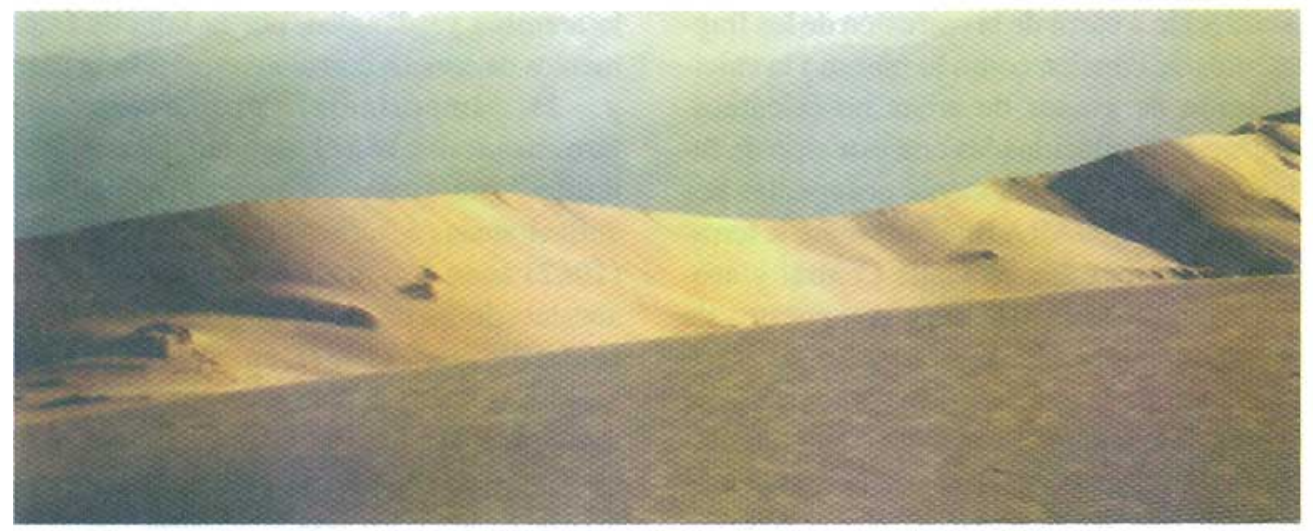

Fig. 28. Mar de Dunas Alto Sur. Sistema tributario sur, delimitando el cono de expansión: duna lineal reversa, pulso 5 (Fig. 26)

Fig. 28. Southern High Sea of Sand. Southern tributary system, limiting th expansion fan: reversing linear dune, pulse 5 (Fig. 26)

los que proceden de mantos de alteración en grus (ARAYA-VERGARA 2000), con teñidos sesquioxídicos indelebles, resistentes al pulimiento, el cual es adquirido en un medio acuático. La operación mecánica de éste debe haber sido cíclica y rítmica, a juzgar por la combinación entre pulimiento y redondez de los granos. La mayor redondez de los fragmentos de concha, parecida a la de los granos de cuarzo más desgastados, sugiere que ambos grupos de arena adquirieron este rasgo en la zona de vaivén de playas con zona de rompiente intermedia de alta energía, que es más efectiva en el pulimiento, según observaciones de ARAYA-VERGARA (inéditas), comparando playas intermedias con reflectivas y disipativas de Chile Central. $\mathrm{Si}$ una parte importante de los vidrios volcánicos (ceniza) es subangulosa, esta fracción parece haber sido agregada a las arenas cuarzosas en forma rápida y resistido como sedimento una acción mecánica más corta. Los ferromagnesianos y líticos pueden corresponder a elementos accesorios o accidentales que acompañan a la ceniza volcánica o a partículas extraidas de la cobertura detrítico volcánica de la región. Pero tanto vidrios como líticos ferromagnesianos deben haber alcanzado a constituir un solo cuerpo sedimentario en playas marinas, cuya influencia hacia el interior es parecida a la observada en otros desiertos. En efecto, si se compara las estructuras «corduroy» de dunas linea- les de los pulsos 2 y 4 con sus homólogas del mar de arenas de Wahiba (Omán) se aprecia que en ambos casos la arena ha conservado una proporción notoria de calcáreo. En Wahiba, aunque éste se halla desde decenas a más de $100 \mathrm{~km}$ de la linea de costa, se concluye que las arenas son de origen litoral (GOUDIE et al. 1987; PEASE et al. 1999). Esto sugiere que en medios dunares de ambientes desérticos el calcáreo puede conservarse por grandes distancias y lapsos de tiempo largos.

Como una de las posibles fuentes de suministro de arenas dunares, la arenisca que constituye el cuerpo de los yardangs parecen representar un ambiente litoral, por la similitud de sus arenas con las de las dunas, su alto contenido de calcáreo y ser vecina a la costa. El problema para su interpretación consiste en su disposición en capas laminares a través de un area extensa de terreno (Fig. 2) y su buzamiento hacia el Sur. Si el ambiente litoral de playa ha sido importante en la composición de las arenas y en la generación del cemento calcáreo de la arenisca, es probable que la estructura laminada corresponda a capas topset de washover fan (capas del techo de delta de derrame), asociado con medios sublagunares (probablemente parálicos) en la edad de funcionamiento de la plataforma de la actual terraza alta. Una vez producido el depósito, el cemento calcáreo debe haber sido 
abastecido a partir de la corrosión de los fragmentos de concha, como lo muestra la calcificación de granos de arena no calcáreos. Estructuras relacionadas con este tipo de facies han sido recientemente observadas por ARAYA-VERGARA (inédito) sobre la terraza marina más alta en Chile Central y asociadas a cordones de playa compuestos de gravas. Conjuntamente, es posible que el buzamiento de las capas corresponda a la deformación tectónica frágil asociada a movimientos verticales costeros en la región, observada por MARQUARDT et al. (2000).

Si esta arenisca es una de las referencias del sistema litoral que generó las arenas dunares, su mayor proporción de calcáreo debe compararse con la de los pulsos dunares. A partir de ella, la disminución paulatina del calcáreo con la antigüedad del pulso dunar puede servir para sustentar la distinción de pulsos en una secuencia temporal. Pero una parte de las arenas, especialmente representada por las dunas lineales del pulso 4 y, secundariamente, por las transverso-transgresivas del pulso 3 , no parece directamente emparentada con la arenisca yardángica, por la falta de fragmentos de concha corroidos en el primer caso y la importante proporción de ferromagnesiano en el segundo. Es más probable que los cordones de playas deflacionadas descritos por SEGERSTROM (1962) sean los más importantes centros abastecedores en estos casos. Al respecto, GOUDIE et al. (1987), en el mar de arena Wahiba (Omán), hallaron rasgos que permiten hipotetizar fuentes distintas de arena, lo que induce a considerar también las diferencias de edad de los sistemas constituyentes.

Con referencia a esto, el lapso de tiempo durante el que se generaron los diferentes pulsos debe haber sido muy grande, si se considera las observaciones en las terrazas marinas. En efecto, PASKOFF (1979) - en un seguimiento de interacciones fluvio-marinas relata depósitos marinos atribuibles al Cuaternario Antiguo sobre la terraza desarrollada entre 90 y $140 \mathrm{~m}$ cerca del río Copiapó. Recientes correlaciones isotópicas de MARQUARDT et al. (2000) señalan que las partes más altas de esta terraza corresponden

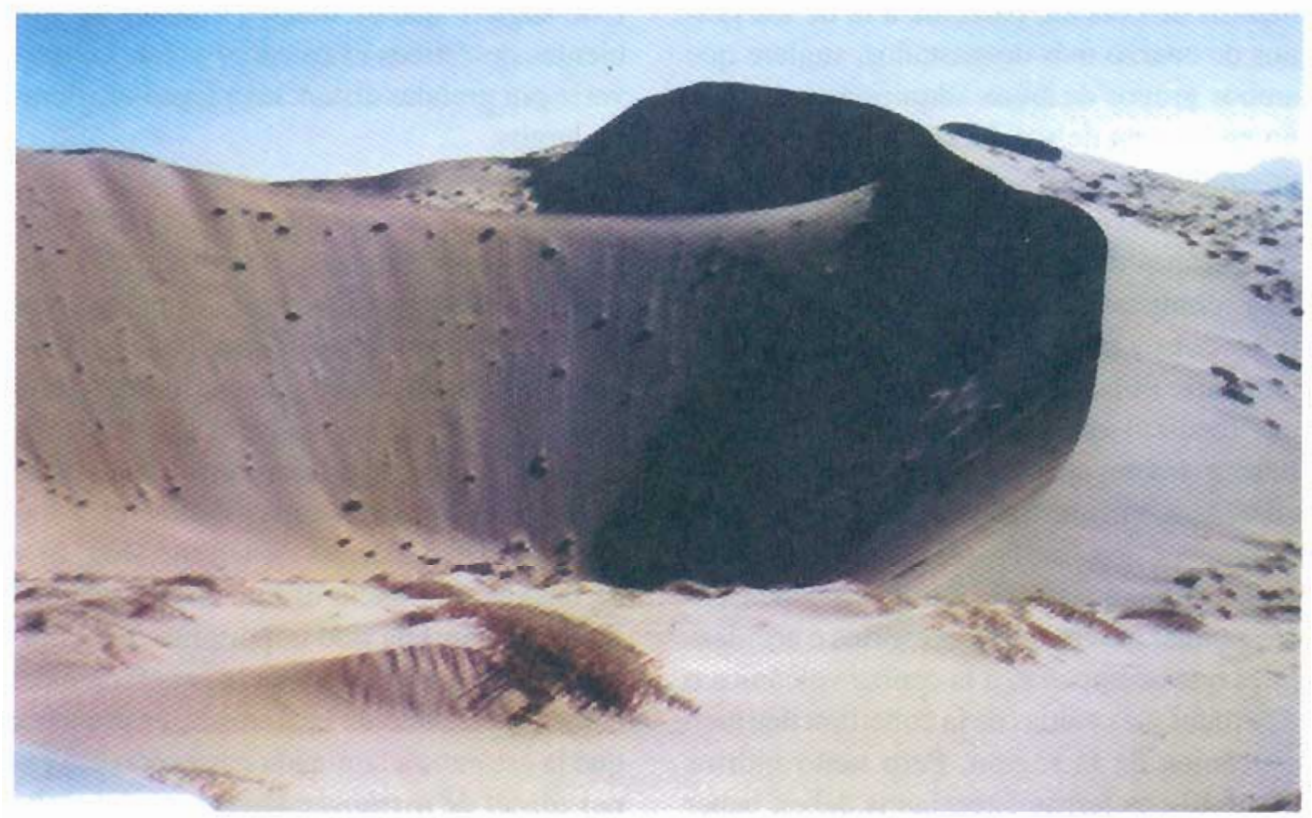

Fig. 29. Mar de Dunas Alto Sur. Parte alta distal del cono de expansión: duna anidada (pulso 5).

Fig. 29. Southern High Sea of Sand. High part of the expansion fan: nested dune, pulse 5 . 
a los estadios isotópicos $9(\sim 330 \mathrm{ka})$ y 11 $(\sim 430 \mathrm{ka})$, lo que sugiere que la terraza de más de $200 \mathrm{~m}$, hasta ahora fuera de correlación isotópica, puede ubicarse en el Pleistoceno Medio a Inferior. Niveles más bajos, del orden de los 60,40 y $30 \mathrm{~m}$, pertenecen a los estadios isotópicos $7(\sim 210 \mathrm{ka})$, $5 \mathrm{e}(\sim 125 \mathrm{ka})$ y $5 \mathrm{c}(\sim 105 \mathrm{ka})$. Consecuentemente, se puede comprender que - durante esta larga sucesión de cambios eustáticos acompañados de activa elevación costera la construcción de los ergs internos debe haberse realizado a través de una secuencia de fases (pulsos), siguiendo además cambios climáticos. Varios estudios, por ejemplo en Anatolia Central (KUZUCUOGLU et al. 1998), consisten en análisis de ergs, cuyos segmentos corresponden a cambios morfoclimáticos. Observaciones en el Kalahari indican que la operación multifásica, asociada a edades más áridas y ventosas, puede explicar la existencia de patrones dunares complejos en los mares de arena (STOKES et al. 1997). Parece ser que los pulsos representan lapsos de acreción más cortos que los de no deposición, de una manera similar a la observada por GOUDIE et al. (2000) en los Emiratos Árabes Unidos. Si se considera la distancia desde los ergs hasta la costa en Atacama y la ubicación de una megaduna (draa) muy interna y separada de los mares de arena principales por extensos glacis y regs ( $\mathrm{C}^{\circ}$ Medanoso, Fig. 1), se deduce que los procesos dunares operaron en el Pleistoceno sobre un área mayor que la actual. Principios similares de observación sugieren lo mismo en ergs estabilizados de Zimbabwe, Zambia y Angola (THOMAS 1984).

La condición de desierto marginal en Atacama, con ausencia de pedogénesis en las dunas, se comprende mejor si se compara con áreas marginales del desierto africano, donde aparece gradualmente el efecto de la pedogénesis con el aumento de la pluviosidad hacia el Sur, como se detecta en el erg de Hausaland al SW de Niger (WHITE 1971) y en el N de Nigeria (NICHOL 1991). Pero en los casos africanos la gradación es hacia clima tropical húmedo y en el chileno, hacia clima templado, donde aparecen arenosoles sobre las dunas costeras más antiguas (ARAYA-VERGARA 1998). O sea, el ecotono zonal en la morfo y pedogénesis dunar se produce entre las latitudes de los ergs de Atacama y las de Chile Central.

Para el gran lapso de tiempo en que deben haberse formado los ergs, es difícil pronunciarse sobre el grado de simultaneidad de los pulsos de igual denominación, si se compara los mares bajos con los altos en cada erg. Mientras no haya dataciones absolutas de ellos, la herramienta para hipótesis es el análisis morfológico realizado. Si a éste se agrega consideraciones aloestratigráfícas (WALKER 1990; LØNNE 1995), el paisaje debe dividirse entre cuencas acumuladoras y cinturones de derivación y de ascenso y descenso. Es probable que, mientras operaron los primeros pulsos en los conos de expansión externos (bajos a medios), el excedente lateral de arena continuara su migración hacia los internos (altos), mediante los cinturones de derivación. Sólo en este tipo de operación y emplazamiento es posible que los pulsos internos y externos sean simultaneos, aunque con una diferencia de tiempo en la construcción de los respectivos mares de arena, siendo los segundos levemente más antiguos que los primeros.

\section{Efectos pluviales y del escurrimiento en la modificación del modelado dunar}

En este aspecto, debe tenerse en cuenta la asociación operativa que puede haber entre vertientes, glacis, regs y mares de arena. Esta asociación está relacionada con tres hechos: la anomalía morfológica en el cono de expansión del Mar de Dunas Medio Sur (abanico de disección), los yardangs y la duna lineal compuesta reversa inyectada o lineal de vertiente asociada al Mar de Dunas Alto Sur. En primer lugar, la anomalía en forma de abanico de disección, interpretada como remodelado fluvial sobre una parte de un mar de dunas, corresponde a interferencias fluviales que pueden ser comunes en los ergs. Por ejemplo, BULLARD \& NASH (1998) observaron variabilidad del patrón de dunas lineales en la vecindad de valles secos en el 
Kalahari SW. En segundo lugar, es posible también relacionar el desarrollo del drenaje con la elaboración de los surcos que explican los yardangs. Ellos parecen resultar de una acción combinada entre el drenaje fluvial y la acción del viento, porque en Bellavista y Pampa Los Caracoles-Buena Vista (Fig. 2) el haz yardángico converge en una confluencia de cuenca de drenaje, aguas debajo de la cual hay un cono de deyección con glacis de derrame. Pero la delineación erosional de los surcos no puede obedecer sólo a la organización de la red de drenaje, puesto que en el sector de Bellavista y Pampa Dura los yardangs más rectilíneos no muestran señal de corresponder a la influencia del drenaje. Además, el patrón de los surcos no corresponde a la estructura dislocada de las areniscas. La delineación erosional puede tener direcciones bien independientes de la estructura, como lo demuestran los análisis de BROOKES (2001) en el Desierto de Libia. Pero en Atacama hay correspondencia con la homogeneidad litológica de las areniscas. En cambio, en Libia las diferencias litológicas se traducen en formas distintas de yardangs (BROOKES 2001). En tercer lugar, la duna lineal reversa es llamada «de vertiente», porque su área de origen indica un abastecimiento coluvial. Experimentos de campo y simulaciones computacionales, acerca de la formación de pavimento del desierto (reg) sugieren efecto importante de las lluvias que afectan las vertientes tanto en redistribución de arenas como en denudación (WAINWRIGHT et al. 1999). El conocimiento de este tipo de fuente de sumunistro de la arena dunar, constituye un avance con respecto a la pobre comprensión del conjunto de retroalimentaciones que operan en los procesos de erosión pluvial en ambientes de desierto.

\section{CONCLUSIONES}

\section{Morfología general de los ergs}

Los ergs de Atacama corresponden a sistemas de desierto de montaña, por lo que su estructura es altamente diferente a las existentes en desiertos de llanura y plateau. En ellos, la dicotomía entre dunas de valle, en cinturón, con efecto de embudo, y dunas de cuenca de expansión, es fundamental para la generalización morfológica. En este contexto, es mejor llamar a estos sistemas ergs de montaña y valle, donde se suceden sistemas de valles y cuencas intermontanas.

\section{Coacción entre la estructuración de los ma- res de arena y la forma de las cuencas preexistentes}

La sucesión de valles y cuencas ha condicionado la coacción entre la estructuración de los mares de arena y la forma de las cuencas preexistentes. Ella se expresa en cuencas acumuladoras separadas por cinturones tributarios y emisarios. Proporcionalmente, estos últimos presentan mayor actividad que las primeras, por el efecto de embudo. En las cuencas acumuladoras con conos de expansión hay generalizada estabilidad, presentándose la actividad con el aumento de altitud. En otras palabras, un bypass entre mares de cuenca significa una secuencia espacial en el orden pasivo-activo-pasivo, donde además operan distintos grados de variabilidad del viento. Si se compara esta realidad con los modelos y consideraciones de WILSON (1971) sobre influencia de formas preexistentes y operación de flujos secundarios en el desarrollo de ergs, se concluye que ella puede considerarse en los modelos y que el sistema de relaciones debe ser mejor investigado.

\section{Etapas de la formación}

Las arenas aportadas desde la costa deben proceder de playas pleistocénicas, aunque la construcción de los sistemas interiores haya continuado en el Holoceno. La edad de los pulsos en el Cuaternario queda por determinarse. El problema del grado de simultaneidad de pulsos de una misma denominación en distintos mares de arena, está relacionado con la relación entre la edad de los sistemas tributario y emisario y la de los acumuladores principales. Las dunas lineales complejas y compuestas de sistemas tributarios y emisarios tienen rasgos de formas polifásicas. 
Mayores observaciones sobre ellas pueden ofrecer nuevos conocimientos evolutivos.

\section{Relación con la teoría general acumulada}

Desde el punto de vista de la estructuración érgica, la teoría morfogenética acumulada ha derivado preferentemente de investigaciones en desiertos de llanura y plateau. Para los de montaña y valle, los resultados obtenidos aquí deben considerarse como un paso para la formación de teoría específica, conjuntamente con el aporte de KUZUCUOGLU et al. (1998) para Anatolia Central, a nivel de erg complejo, y los trabajos sobre interferencia topográfica citados más atrás.

Desde el punto de vista zonal, se fortalece la aplicación del concepto de ergs de desierto marginal, siguiendo la idea de MORTENSEN 1927, pudiéndose además hacer comparaciones sobre gradaciones zonales, por ejemplo con África. Complementariamente, se demuestra los tipos de fuente de la masa arenosa distinguidos clásicamente por BRUGGEN (1950) y SEGERSTROM (1962), a lo que hay que agregar que ellos tienen relación geosinergética con la primera cuenca fluvial con escurrimiento perenne hacia el mar en el borde de un desierto hiperárido. Debido a la especificidad zonal de estas formas, la noción de Formenschatz de MORTENSEN (1927) hay que traducirla en su significado más profundo, como un valioso conjunto atesorado, de formas que han interaccionado morfoclimáticamente.

\section{AGRADECIMIENTOS}

El autor agradece la invitación y el apoyo del Sr. Daniel Sepúlveda, Secretario Regional Ministerial de la Vivienda, Región de Atacama, que hizo posible su misión de terreno, en el verano del 2000. La Sra. Marcela Luci Palma, geógrafa asociada a estos temas en la región, fue una importante gestora de esta misión de terreno y gabinete, aportando la más amplia información posible. El equipo profesional de la Secretaría Ministerial prestó su decisiva ayuda en Copiapó. Los miembros de las asociaciones de raid hicieron posible el acceso al campo con sus vehículos «todo terreno», colaborando en esto muy espedita y gentilmente. El Prof. Roland Paskoff de la Universidad de Lyon, Francia, hizo una constructiva revisión crítica del manuscrito.

\section{REFERENCIAS}

ANDERSON, R.S., 1996. The attraction of sand dunes. Nature, 379: 24-25.

ARAYA-VERGARA, J.F., 1987. The evolution of modern coastal dune systems in Central Chile. In: Gardiner, V. (Ed.), International Geomorphology 1986 Part II. John Wiley \& Sons, Chichester: 1231-1239.

ARAYA-VERGARA, J.F., 1989. Remnant coastal dunes and their significance in Chilean ergs. Geoöko-Plus, 1: 15.

ARAYA-VARGARA, J.F., 2000. Desarrollo de superficies de aplanamiento disectadas sobre coast range en la Región del Maule, Chile Central. Invest. Geogr. Chile, 34: 77104.

ARENS, S.M., 1996. Patterns of sand transport on vegetated foredunes. Geomorphology, 17: 339-350.

BAGNOLD, R.A., 1984. The physics of blown sand and desert dunes. Chapman \& Hall, London, 5th Repr.

BIGARELLA, J.J., 2000. Parabolic dune behavior under effective storm wind conditions. R. Brasileira de Geomorf., 1(1): 1-26.

BIRD, E.C.F., 1984. Coasts: An Introduction to Coastal Geomorphology. Third Ed. Basil Blackwell, Oxford.

BRÜGGEN, J., 1950. Fundamentos de la geología de Chile. Ed. I.G.M., Santiago.

BROOKES, I.A., 2001. Aeolian erosional lineations in the Libyan Desert, Dakhla Region, Egipt. Geomorphology, 39: 189-209. 
BULLARD, J.E. \& D.J. NASH, 1998. Linear dune pattern variability in the vicinity of dry valleys in the southwest Kalahari. Geomorphology, 23: 35-54.

BULLARD, J.E., D.S.G. THOMAS, I. LIVINGSTONE \& G.F.S. WIGGS, 1995. Analysis of linear sand dune morphological variability, southwestern Kalahari Desert. Geomorphology, 11: 189-203.

COOKE, R.U. \& A. WARREN, 1973. Geomorphology in deserts. California University Press, Los Angeles.

COOKE, R.U., A. WARREN \& A.S. GOUDIE, 1993. Desert Geomorphology. University College Press, London.

CRAIG, M.S., 2000. Aeolian sand transport at the Lanphere dunes, Northern California. Earth Surf. Process. Landforms, 25: 239-253 GAY Jr., S.P., 1999. Observations regarding the movement of barchan sand dunes in the Nazca to Tanaca area of southern Peru. Geomorphology, 27: 279-293.

GOUDIE, A.S., A. WARREN, D.K.C. JONES \& R.U. COOKE, 1987. The character and possible origins of the aeolian sediments of the Washiba sand sea, Oman. Geogr. J., 153(2): 231-256.

GOUDIE, A.S., S. STOKES, I. LIVINGSTONE, I.K. BAILIFF \& R.J. ALLISON, 1993. Post-depositional modification of the linear sand ridges of the West Kimberley area of north-west Australia. Geogr. J., 159(3): 306-317.

GOUDIE,A.S., A.COLLS, S. STOKES,A. PARKER, K. WHITE \& A. AL-FARRAJ, 2000. Latest Pleistocene dune construction at the north-eastern edge of the Rub Al Khali, United Arab Emirates. Sedimentology, 47: 1011-1021.

GROVE, A.T., 1958. The ancient erg of Hausaland, and similar formations on the south side on the Sahara. Geogr. J., 124(4): 528-533.
HESP, P., W. ILLENBERGER, I. RUST, A. MC LACHLAN \& R. HYDE, 1989. Some aspects of transgressive dunefield and transverse dune geomorphology, south coast, South Africa. Z. Geomorph. N.F., Suppl-Bd. 73: 111-123.

HOWARD, A.D., J.B. MORTON, M. GAD-EL-HAK \& D.B. PIERCE, 1978. Sand transport model of barchan dune equilibrium. Sedimentology, 25: 307-338.

JIMENEZ, J.A., L.P. MAIA, J. SERRA \& J. MORAIS, 1999. Aeolian dune migration along the Ceará coast, north-eastern Brazil. Sedimentology, 46: 689-701.

KAR, A., 1990. Megabarchanoids of the Thar: their environment, morphology and relationships with longitudinal dunes. Geogr. J., 156(1): 51-61.

KRUMBEIN, W.C. \& L.L. SLOSS, 1969. Estratigrafía y sedimentación. UTEHA, México. Trad.

KUZUCUOGLU, C., R. PARISH \& M. KARABIYICOGLU, 1998. The dune systems of the Konia Plain (Turkey): their relation to environmental changes in Central Anatolia during the Late Pleistocene and Holocene. Geomorphology, 23: 257-271.

LØNNE, I., 1995. Sedimentary facies and depositional architecture of ice-contact glaciomarine systems. Sedim. Geol., 98: 1343.

MCKENNA NEUMAN, C., N. LANCASTER \& W.G. NICKLING, 2000. The effect of unsteady winds on sediment transport on the stoss slope of a transverse dune, Silver Peak, NV, USA. Sedimentology, 47: 211-226.

MARQUARDT, C., A. LAVENU \& L. ORTLIEB, 2000. Neotectónica costera en el área de Caldera $\left(27^{\circ}-28^{\circ} \mathrm{S}\right)$, Norte de Chile. En: IX Congreso Geológico Chileno, Puerto Varas, Chile. Actas, Vol. 2, pp. 588-592. 
MECKELEIN, W., 1987. Land use problems in the Chinese deserts. Applied Geogr. and Development, 30: 7-29.

MOMIJI, H. \& A. WARREN, 2000. Relation of sand trapping efficiency and migration speed of transverse dunes to wind velocity. Earht Surf. Process. Landforms, 25: 1069-1084.

MOMIJI, H., R. CARRETEROGONZÁLEZ, S.R. BISHOP \& A. WARREN, 2000. Simulation of the effect of wind speedup in the formation of transverse dune fields. Earth Surf. Process. Landforms, 25: 905-918.

MORTENSEN, H., 1927. Der Formenschatz der nordchilenischen Wüste. Abh. Ges. Wissensch., Göttingen, 12.

MORTIMER, C., 1973. The Cenozoic history of the southern Atacama Desert, Chile. J. Geol. Soc. Lond., 129: 505-526.

MOUNTNEY, N. \& J. HOWELL, 2000. Aeolian architecture, bedform climbing and preservation space in the Cretaceous Etjo Formation, NW Namibia. Sedimentology, 47: 825-849.

NICHOL, J.E., 1991. The extent of desert dunes in northern Nigeria as shown by image enhancement. Geogr. J., 157(1): 13-24.

PASKOFF, R., 1979. Un exemple de raccord fluvio-marin: les terrasses du cours inférieur du Rio Copiapó, désert d'Atacama, Chili. C.R.somm. Soc. géol. Fr., 1: 30-33.

SEGERSTROM, K., 1962. Deflated marine terrace as a source of dune chains, Atacama province, Chile. U.S. Geol Survey Prof. Paper 450C: 91-93.

STOKES, S., D.S.G. THOMAS \& P.A. SHAW, 1997a. New chronological evidence for the nature and timing of linear dune development in the southwest Kalahari Desert. Geomorphology, 20: 81-93.
STOKES, S., D.S.G. THOMAS \& R.W. WASHINGTON, 1997b. Multiple episodes of aridity in Southern Africa since the interglacial period. Nature, 388: 154-158.

TASTET, J.P. \& N.I. PONTEE, 1998. Morpho-chronology of coastal dunes in Médoc. A new interpretation of Holocene dunes in Southwestern France. Geomorphology, 25: 93-109.

THOMAS, D.S.G., 1984. Ancient ergs of the former arid zones of Zimbabwe, Zambia and Angola. Trans. Inst. Br. Geogr. N.S., 9(1): 75-88.

TINLEY, K.L., 1985. Coastal dunes of South Africa. South African National Scientific Programmes, Report $\mathrm{N}^{\circ}$ 109,Pretoria.

TRICART, J., 1965. Algunas observaciones geomorfológicas sobre las terrazas del río Copiapó. Inform. geogr. Chile, 15: 45-59.

VAN BOXEL, J.H., S.M. ARENS' \& P.M. VAN DIJK, 1999. Aeolian processes across transverse dunes. I: Modelling the air flow. Earth Surf. Process. Landforms, 24: 255-270.

VAN DIJK, P.M., S.M. ARENS \& J.H. VAN BOXEL, 1999. Aeolian processes across transverse dunes. II: Modelling the sediment transport and profile development. Earth Surf. Process. Landforms, 24: 319-333.

VERSTAPPEN, H.Th., 1968. On the origin of longitudinal (seif) dunes. Z. Geomorph. N.F., 12: 200-220.

VERSTAPPEN, H. Th., 1972. On dune types, families and sequences in areas of unidirectional winds. Hans Poser Festschrift. Göttinger Geogr. Abh., 60: 341-353.

WAINWRIGHT, J., A.J. PARSONS \& A.D. ABRAHAMS, 1999. Field and computer simulation experiments on the formation of desert pavement. Earth Surf. Process. Landforms, 24: 1025-1037. 
WALKER, A.S., 1986. Eolian landforms. In: Short, N.M. \& R.W. Blair Jr. (Eds.), Geomorphology from Space. NASA, Washington, DC, pp. 447-520.

WALKER, I.J., 1999. Secondary airflow and sediment transport in the lee of a reversing dune. Earth Surf. Process. Landforms, 24: 437-448.

WALKER, R.G., 1990. Facies modelling and sequence stratigraphy. J. Sedim. Petrol., 60: 777-786.

WASSON, R.J., K. FITCHETT, B. MACKEY \& R. HYDE, 1988. Large-scale patterns of dune type, spacing and orientation in the Australian continental dunefield. Australian Geogr., 19 (1): 89-104.
WERNER, B.T., 1995. Eolian dunes: computer simulation and attractor interpretation. Geology, 23: 1007-1010.

WHITE, I.P., 1971. The ancient erg of Hausaland in south-western Niger. Geogr. J., 137(1): 69-73.

WIGGS, G.F.S., 2001. Desert dune processes and dynamics. Progress in Phys. Geogr., 25(1): 53-79

WILSON, I.G., 1971. Desert sand flow basins and a model for the development of ergs. Geogr. J., 137: 180-199.

ZAO SONGQIAO \& XIA XUNCHENG, 1984. Evolution of the Lop Desert and the Lop Nor. Geogr. J., 150(3): 311-321.

\section{Esquema de Investigaclones GEOEn/FICAS}

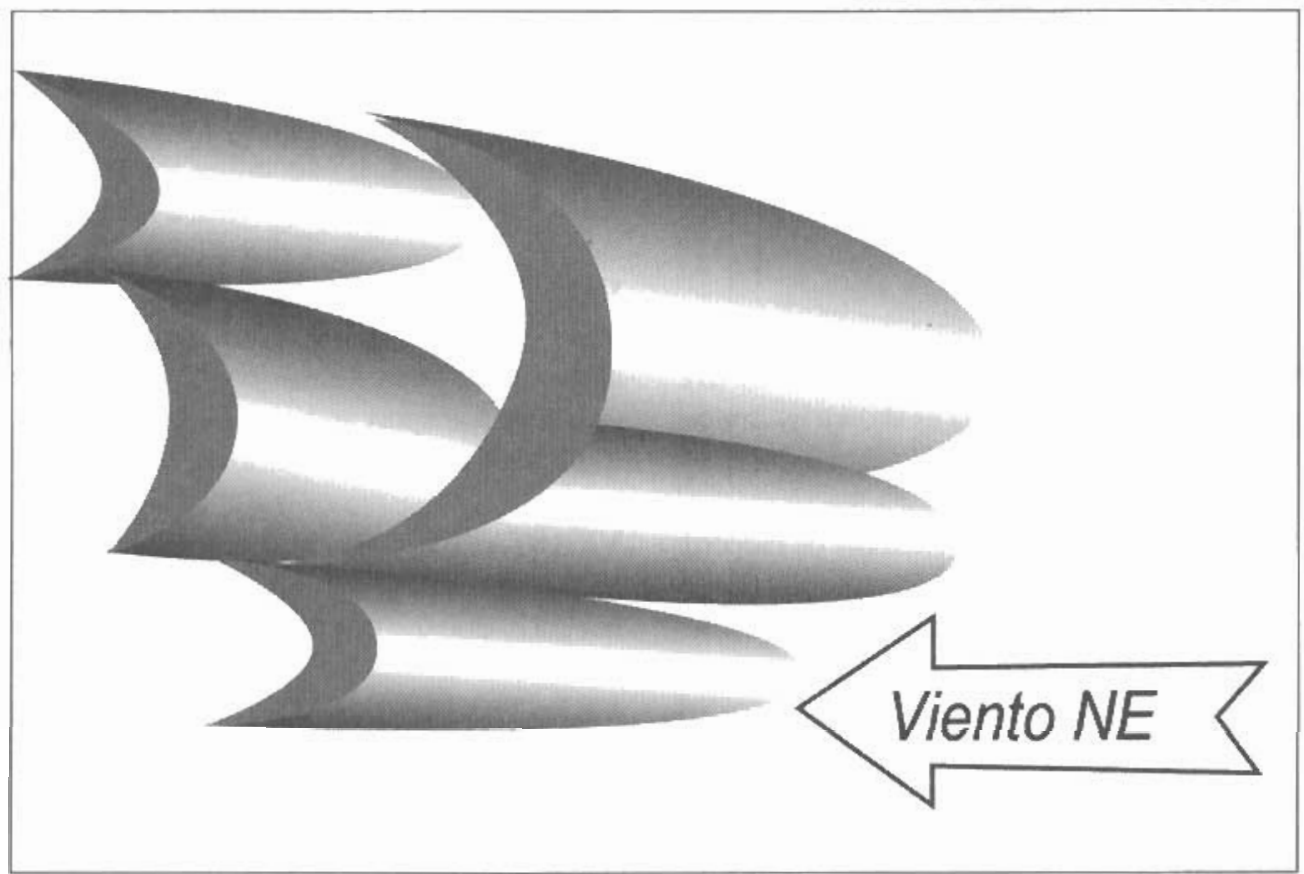

Esquematización de un barján compuesto en el Rock Garden de Marte, deducida de una imagen de terreno captada en la misión Pathfinder, NASA, 1997 (Newcott, D.R., 1998. Return to Mars. Nat. Geogr .Mag., 194(2): 2-29). Se trata de dunas pequeñas, de altura decimétrica y planta métrica, formadas sobre un campo de ventifactos.Si se las compara con dunas barjánicas del pulso 5 de los ergs de Atacama en la Tierra (en este número), se encuentra que esta estructuración debe obedecer a las mismas leyes genéticas para ambos planetas. Dibujo: J.F. Araya Vergara. 